\title{
A REVIEW OF THE LITERATURE RELATING TO THE NORMAL DENSITIES OF GASES
}

\author{
By Marion Smith Blanchard and S. F. Pickering
}

\begin{abstract}
This paper consists of a review of the literature on the normal densities of gases wherein the attempt is made to choose the most reliable value for each gas. The number of sources of the gas in question, the methods used for its purification, the precautions observed in making the experimental measurements, the number of observations made, the agreement between observations of a set and the concordance between the results of the different observers have all been carefully considered in the selection of the final value. While many of the early determinations of historical interest have been included, in general, only those which should be considered in selecting the final value have been critically reviewed.
\end{abstract}

\section{CONTENTS}

I. Introduction and density of air................

II. Densities of various gases.-

1. Acetylene.......

2. Ammonia

3. Argon

4. Carbon dioxide...

5. Carbon monoxide_

6. Chlorine

7. Ethane..........

8. Ethylene........

9. Fluorine

10. Helium

11. Hydrogen .......

12. Hydrogen b r omide..........

13. Hydrogen chloride

14. Hydrogen s u lphide........

15. Krypton

16. Methane $83669^{\circ}-26$
Page

142

144

144

145

148

150

151

151

152

153

154

154

155

157

158

159

160

161
II. Densities of various gasesContinued.

17. Methyl chloride.-

18. Methyl ether.....-

19. Methyl fluoride.--

20. Neon_.._.... 163

21. Nitric oxide...... 164

22. Chemical nitrogen_-_...-...- 165

23. Atmospheric nitrogen_......... 166

24. Nitrous oxide----- 168

25. Oxygen _.......... 169

26. Phosphine_..... 170

27. Propane._...... 170

28. Silicon tetrafluoride_........ 171

29. Sulphur dioxide_- 172

30. Xenon

III. Conclusion............. 173

62 \section{.}

tra

${ }_{173}$
(1) \section{6} 168 169

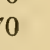




\section{INTRODUCTION AND DENSITY OF AIR}

In the following review of the literature on the normal densities of gases an attempt is made to choose the most reliable value for each gas. The number of sources of the gas in question, the methods used for its purification, the precautions observed in making the experimental measurements, the number of observations made, the agreement between observations of a set, and the concordance between the results of the different observers have all been carefully considered in the selection of an accepted value. While some attention has been given to the best of the early determinations, as indicating the development of the subject, in general, only those which should be considered in selecting the final value have been mentioned. The excellent review which Guye ${ }^{1}$ published in 1907 has been of great value in the preparation of this paper.

Results are expressed in terms of the weight in grams of a normal liter; that is, the weight of a liter of the gas under consideration at $0^{\circ} \mathrm{C}$. and under a pressure of $760 \mathrm{~mm}$ of mercury (at $0^{\circ} \mathrm{C}$.). The value $980.665 \mathrm{~cm}$ per second per second agreed upon by the International Conference on Weights and Measures for the acceleration of gravity is used, and all figures have been corrected to this value.

The first and most frequently used of the accurate methods for determining the densities of gases is that introduced by Regnault, ${ }^{2}$ which is called the "balloon method." It consists in weighing a rigid container or "balloon" of known volume, first full of the gas, then evacuated. A counterpoise of equal volume was used by Regnault to compensate for the buoyant effect of the air, and a correction was made for the compressibility of the gas but not for the difference in the volume of the balloon filled and evacuated. Rayleigh was the first to apply this correction. The famous laboratory of physical chemistry at the University of Geneva has probably carried this method to its greatest perfection. The more important features of the procedure as outlined by Guye ${ }^{3}$ are as follows. In all possible cases the gas is purified by fractional distillation. Two or three balloons with walls of medium thickness and capacities of not more than 1 liter are filled simultaneously. After weighing they are evacuated only to 1 to $2 \mathrm{~mm}$, the residual pressure being measured with a vacuometer. No correction is made for gas adsorbed on the surface of the balloon, but the usual corrections for compressibility and for gravity are applied to reduce the value found to the weight of a normal liter.

1 Guye, J. chim. phys., 5, p. 205; 1907; J. Am. Chem. Soc., 30, p. 145; 1908.

${ }^{2}$ Regnault, Mém. de l'Académie, 21, p. 121; 1847.

3 Guye, J. chim. phys., 11, p. 320; 1913. 
Probably the second in importance of the methods used for the determination of gas densities is the one commonly called the volumeter method. In this a known volume of gas is evolved from or absorbed in a weighed apparatus of relatively small volume. This allows a large volume of gas to be measured while avoiding many of the difficulties in weighing balloons with their large volumes and surfaces.

A large number of important determinations have involved the relative weights of air and of the gas the density of which was to be measured. Leduc ${ }^{4}$ in particular computed the specific gravities, referred to air, of many gases and obtained very close checks with his experimental values. Leduc's computations involved a knowledge of the critical constants and the coefficients of compressibility of the gases. He determined the coefficients of compressibility experimentally, but in most cases he used the data obtained by other observers for the critical constants.

By the introduction of the weight of a normal liter of air a certain amount of accuracy is sacrificed, for although the density of air has been determined with the same care as the densities of other gases, the results obtained by the different observers do not agree as well as the results obtained by these same men for gases such as carbon dioxide, oxygen, and nitrous oxide. The explanation for this is, according to Guye, ${ }^{5}$ the variation in the composition of the air in different places and at different times. It has actually been found that a decided increase in barometric pressure about the time the sample of air is taken is generally accompanied by a decrease in the density because the upper air which comes to the earth's surface during such conditions contains a larger proportion of the lighter elements of the atmosphere.

The variations in the composition of the air from time to time in a given locality are greater than the variations with locality. The determination of the relative densities of air and another gas is generally simpler than the determination of the absolute density of either. For these two reasons the use of an average value for the weight of a normal liter of air for computing the weight of a gas which has been compared with air appears preferable to the use of a particular value obtained by the observer who made the comparison, unless the determination of the specific gravity of the gas and the absolute weight of the air were made at the same time.

The values of the weight of a normal liter of dry air free from carbon dioxide given by various observers are listed in Table 1 .

4 Leduc, Ann. chim. phys. (7), 15, p. 90; 1898.

5 Guye, J. chim. phys., 15, p. 561; 1917. See also Jaquerod and Borel, J. chim. phys., 19, p. 11; 1921. 
TABLE 1.-Weight of a normal liter of air

\begin{tabular}{|c|c|c|c|c|}
\hline Date & $\begin{array}{c}\text { Weight } \\
\text { of a nor- } \\
\text { mal liter } \\
\text { of air } \\
\text { (grams) }\end{array}$ & Place & Observer & Reference \\
\hline $\begin{array}{l}1806 \\
1847 \\
1879 \\
1893 \\
1898 \\
1912 \\
1914 \\
1916 \\
1921 \\
1922 \\
\text { Mean. }\end{array}$ & \begin{tabular}{|l|}
1.2991 \\
1.29282 \\
1.29314 \\
1.29290 \\
1.29279 \\
1.2930 \\
1.29303 \\
1.29279 \\
1.2928 \\
11.29318 \\
1.29293 \\
\end{tabular} & 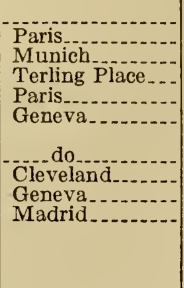 & 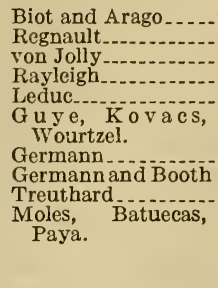 & $\begin{array}{l}\text { Mém. de l'Institute, } \boldsymbol{7}, \text { p. } 301 ; 1806 . \\
\text { Mém. de l'Académie, 21, p. 143; } 1847 . \\
\text { Wied. Annalen (2), 6, p. 520; } 1879 . \\
\text { Proc. Roy. Soc. (London), 53, p. 134; } 1893 . \\
\text { Ann. chim. phys., 15, p. 1; 1898. } \\
\text { J. chim. phys., 10, p. 332; 1912. } \\
\text { J. chim. phys., 12, p. 107; 1914. } \\
\text { Western Reserve Univ. Bull., 19, p. } 15 ; 1916 . \\
\text { Compt. rend., 172, p. 1598; 1921. } \\
\text { Anales Soc. españ. fís. quím., 20, p. } 34 ; 1922 .\end{array}$ \\
\hline
\end{tabular}

1 Corrected by Paya and Moles. Anales Soc. españ. fís. quím., 20, p. 247; 1922.

The results preceding those of Rayleigh are of historical interest only and are not included in the calculated mean.

The average weight of a normal liter of air is accepted as 1.2929, and this value is used throughout this paper in computing the densities of gases from the observed specific gravities referred to air.

The remaining gases are considered in alphabetical order. Unless otherwise mentioned, the method used in each case is that above described as the "balloon method."

\section{DENSITIES OF VARIOUS GASES}

\section{ACETYLENE}

Leduc ${ }^{6}$ did not feel sure enough of the purity of the acetylene with which he worked to make more than one determination. This one gave 1.1708 as the weight of a normal liter.

Maass and Russell ${ }^{7}$ used a variation of the volumeter method, measuring the volume of the gas in a large bulb at $0^{\circ}$, condensing the gas, and weighing it as a liquid in a sealed bulb at room temperature. The acetylene was not purified with sufficient care to render the result obtained, 1.1695, uncorrected for gravity, of much importance.

Stahrfoss ${ }^{8}$ followed the procedure adopted by the laboratory at Geneva. The gas was prepared by dropping into water a powdered mixture of crystallized calcium carbide and potassium bichromate with a little iron chloride and was purified by passing it through potassium hydroxide, mercuric chloride, more potassium hydroxide, and finally phosphorus pentoxide. The value found for the normal density was 1.1792 .

${ }^{6}$ Leduc, Ann. chim. phys. (7), 15, p. 35; 1898.

7 Maass, O., and Russell, J., J. Am. Chem. Soc., 40, p. 1847; $191 \mathrm{~s}$.

s Stahrfoss, Arch. sci. phys. nat. (1), 28, p. 351; 1914; J. chim. phys., 13, p. 175; 1818. 
Although this work was very carefully carried out, the value obtained is rather high, inasmuch as the ratio between the observed density and that calculated from the molecular weight is much greater than the ratios for other gases having densities or boiling points of the same order of magnitude (see fig. 1, p. 174). Until additional determinations are made it would appear best to use 1.179.

\section{AMMONIA}

Leduc ${ }^{9}$ was the first to make any accurate determination of the density of ammonia. He used commercial ammonia, purified by a double fractional distillation and dried with fused potassium hydroxide. His observations give 0.7720 for the weight of a normal liter.

Guye and Pintza ${ }^{10}$ were not satisfied that the gas used by Leduc was sufficiently purified. They distilled commercial ammonia through lime heated to redness. The amines present were thus transformed to hydrocarbons and ammonia gas, the latter being absorbed in a solution of hydrochloric acid. The ammonium chloride formed was crystallized, and the ammonia was set free by treatment with calcium oxide and dried over columns of fused potassium hydroxide. The volumeter method of determining the density was used, the measuring vessel having a capacity of 3.5 liters. The mean of five determinations gave 0.77083 as the weight of a normal liter, the greatest variation from the mean being 2 in 7,700 .

This lower value for the density of ammonia was confirmed by Perman and Davies. ${ }^{11}$ They used two procedures in their researches(1) the volumeter method in which the ammonia was measured in a vessel of 1.7783 liters capacity and was absorbed in concentrated sulphuric acid before weighing, and (2) the balloon method employing one 0.5-liter balloon. The gas was obtained from four different sources- $-(a)$ commercial anhydrous ammonia from an iron cylinder; (b) commercial ammonia purified by the method employed by Guye and Pintza, except that sodium hydroxide was substituted for the calcium oxide to free the ammonia gas from the ammonium chloride; (c) ammonium oxalate, 10 times crystallized and then treated with potassium hydroxide; and $(d)$ sodium nitrite reduced with aluminum and sodium hydroxide, the ammonia being absorbed in hydrochloric acid and freed with sodium hydroxide.

Several experiments were made to determine whether or not sufficient ammonia was adsorbed on the glass to affect the results. A globe was filled with ammonia above atmospheric pressure and allowed to stand 12 hours; after allowing the excess ammonia to escape the usual number for the density was obtained. A globe filled

2 Leduc, Compt. rend., 125, p. 571; 1897; Ann. chim. phys. (7), 15, p. 35; 1898.

10 Guye and Pintza, Compt. rend., 111, p. 51; 1905.

11 Perman and Davies, Proc. Roy. Soc. (London), 73A, p. 28; 1906. 
with ammonia and exhausted to $0.1 \mathrm{~mm}$ showed no change of pressure, as read by a cathetometer, for several days. Globes of 0.50 liter and 1.77 liters capacity yielded the same results. The authors concluded that no appreciable ammonia was adsorbed or condensed on the glass surfaces. The results obtained were as follows:

\begin{tabular}{|c|c|c|c|}
\hline Method & Source of gas & $\begin{array}{c}\text { Number } \\
\text { of deter- } \\
\text { minations }\end{array}$ & $\begin{array}{l}\text { Weight of } \\
\text { a normal } \\
\text { liter }\end{array}$ \\
\hline $\begin{array}{l}1 \\
1 \\
2\end{array}$ & $\begin{array}{l}(a),(b),(c)-(a),(b) \\
(d),(b)\end{array}$ & $\begin{array}{l}4 \\
7 \\
4\end{array}$ & $\begin{array}{l}0.7717 \\
.77089 \\
.77090\end{array}$ \\
\hline
\end{tabular}

The high value which was found for the commercial ammonia, not carefully purified, substantiates the supposition that the gas used by Leduc was not entirely free from pyridine. The authors chose to consider the second value, 0.77089 , as the most accurate. Guye $^{12}$ in his review of researches on the density of gases gave 0.7708 as the most reliable value for the density of ammonia.

Scheuer ${ }^{13}$ prepared ammonia from ammonium sulphate which he obtained by the action of sulphuric acid on ammonium chloride purified by recrystallization. Elaborate precautions were taken to insure the purity of the sample. No significant differences were obtained for balloons of different sizes so no correction for adsorption was made. The mean of 16 determinations was 0.77081 $(g=980.665)$, the greatest deviation from the mean being 0.00026 .

McKelvy and Taylor ${ }^{14}$ purified ammonia from several sources with extreme care. Reliance was not placed only upon the methods of preparation, but the samples before and after purification and at various stages in the process were analyzed by methods which would detect extremely small amounts of the impurities ordinarily present.

The most important of these methods of analysis was the combustion of a considerable volume of ammonia with oxygen, and the determination of carbon dioxide, if any resulted. This, of course, showed the presence of any carbon compound whatever. A delicate method for determining noncondensing gases was also employed. The noncondensing gases were found to be the impurity hardest to eliminate. For a complete discussion of the methods of purification the original paper must be consulted. The following is an example:

A sample of liquid ammonia of unusual purity was distilled through lime heated to redness to destroy amino compounds. Approximately one-third of the ammonia was decomposed into hydrogen and nitrogen by this process. The remaining ammonia was absorbed in sulphuric acid, the ammonium sulphate recrystalized and fused and then

${ }^{12}$ Guye, J. Am. Chem. Soc., 30 p. 143; 1908.

13 Scheuer, Sitz. Akad. Wiss. Wien., 123, p. 931; 1914.

14 McKelvy and Taylor, B. S. Sci. Paper No. 465; 1923. 
dissolved in distilled water. Sodium hydroxide was added, and the liberated ammonia was treated with potassium hydroxide, freshly ignited lime, and barium oxide. It was then liquefied and subjected to fractional distillation six times. The liquid was then boiled so vigorously at reduced pressure that it solidified and the vapors were pumped off. This solid was then subjected to fractional sublimation, and the space above the sublimate, cooled by liquid air, was highly evacuated. The ammonia was then allowed to melt and again boiled by evacuation until it solidified. The ammonia thus prepared was transferred by distillation to the apparatus in which its physical property was to be determined and was solidified by means of liquid air, the container evacuated and sealed with the vacuum pump still in operation.

Numerous samples prepared by this and other elaborate methods were weighed by both the balloon and volumeter methods by Taylor. The results were consistently higher than those obtained by other careful experimenters, but no explanation of the discrepancy could be found. Partly for this reason Taylor did not publish the observations on density, which led to 0.7713 for the weight of a normal liter.

One of the samples of ammonia prepared by McKelvy and Taylor was used for density determinations by Meyers and Jessup. ${ }^{15}$ This sample had been obtained by the purification of a sample of synthetic ammonia which at the start showed no impurity except water. This material was dried with metallic sodium and fractionally distilled 18 times at various pressures. It was then subjected to a fractional sublimation, after which it was twice liquefied and again frozen by rapid boiling in vacuum. Whereas Taylor made density determinations with glass apparatus and made no correction for adsorption, Meyers and Jessup determined the density by using metal bombs especially constructed to permit the determination of specific volume at various pressures and temperatures. These metal containers showed an appreciable amount of adsorption, and several containers were employed having known areas of metallic surface exposed to the gas. The difference in the observed density permitted a correction to be made for adsorption. This correction was applied to three determinations of the density, two of which differed by $0.0013 \mathrm{~g}$ per liter. The mean value, 0.7713 , is identical with that given by Taylor.

The decided difference in the weight of a normal liter found in these observations at the Bureau of Standards and those obtained by the several other careful observers has not been explained. It is of interest to note that the weight of a normal liter computed from the molecular weight and the compressibility of ammonia between 0 
and 1 atmosphere (1.0151), reported by Maverick, ${ }^{16}$ agrees exactly with the weight of a normal liter found at the Bureau of Standards, if it is assumed that the limiting value of $p v$ at zero pressure is the same as that for oxygen.

Neither the careful work of Guye and Pintza, Perman and Davies, and Scheuer, nor that of Taylor, and Meyers and Jessup can be ignored in selecting a value for the density of ammonia. The weight of a normal liter chosen is therefore 0.7710 , with an uncertainty of two or three units in the last decimal place.

\section{ARGON}

The density of argon (referred to oxygen as 16) was determined by Ramsey, ${ }^{17}$ who used gas isolated from atmospheric nitrogen by means of hot magnesium. The absorption by magnesium was continued until the gas showed no further contraction or spectroscopic evidence of nitrogen. The mean of four determinations was 19.941 (referred to oxygen as 16). Two other determinations were rejected because of a trace of nitrogen.

Rayleigh ${ }^{18}$ made his determinations with argon from which nitrogen had been removed by means of an electric discharge in the presence of oxygen, the nitrogen oxides being absorbed by an alkaline solution. The sparking was continued until no nitrogen could be detected either by contraction, variation in the density, or by means of a spectroscope. Out of seren determinations three were accepted, the mean of these being 19.940 (referred to oxygen as 16).

From these two results, which agreed so well, Guye ${ }^{19}$ calculated the weight of a normal liter to be 1.7810. Rayleigh and Ramsay, however, took no account of the helium present in the argon prepared by their method. Assuming the proportions of helium, neon, xenon, and krypton, which were found in the air by Ramsay, and the proportion of argon found by Schloesing and by Kellas, Guye calculated the percentage of error in their results. Allowing for these impurities, the weight of a normal liter would be 1.7825 . This agrees much more closely with later results.

Ramsay made some more determinations in 1898 with the help of Travers. ${ }^{20}$ The argon was prepared by passing air freed from water and carbon dioxide first over heated metallic copper to remove the oxygen, then over heated metallic magnesium, next orer a mixture of red-hot anhydrous lime and magnesium powder, and lastly orer red-hot copper oxide. It was liquefied and the helium and neon

${ }_{16}$ Marerick, Thesis Université de Genève, 1923. This thesis includes with the experimental work a review of the observations of others which are in excellent accord with those of the author.

17 Ramsay, Trans. Roy. Soc. (London) (A), 186, p. 187, 1895.

18 Rayleigh, Proc. Roy. Soc. (London), 59, p. 198, 1896; Nature, 57, p. 209; 1898.

10 Guye, J. chim. phys., 5, p. 203; 1907.

20 Ramsay and Travers, Proc. Roy. Soc. (London), 64, p. 183; 1895 
removed by fractional distillation. The mean of four determinations, again referred to oxygen as 16 , with a bulb of 33 cc capacity was 19.95 , and the mean of four with the large bulb, of 163.19 cc capacity, was 19.957. The weight of a normal liter calculated from this is 1.7824 .

Schultze ${ }^{21}$ used an entirely different method of preparation. He absorbed the nitrogen and oxygen simultaneously by circulating the air in an iron tube containing calcium carbide heated to $1,100^{\circ} \mathrm{C}$. The gas was then passed over hot copper oxide to remove any hydrogen which might be present, and further purified with potassium hydroxide, sulphuric acid, and phosphorus pentoxide. The cycle was repeated a few times, and then the argon was separated from helium and neon by absorbing it in cooled charcoal. The density determinations were carried on over a considerable period of time and the argon tested spectroscopically at intervals to insure its purity. The mean of three determinations was $1.78376 \pm 0.00035$ for the weight of a liter at $0^{\circ} \mathrm{C}$. and $760 \mathrm{~mm}$. No mention is made of gravity. If correction is applied for the difference between the value of gravity at the place of observation and the standard value $(g=980.665)$, the above mean becomes 1.7824 .

Fischer and Hahnel ${ }^{22}$ purified argon in the same manner as did Schultze, except that they do not mention any precautions for the remoral of neon or helium. The mean of seren determinations gave 19.945 (referred to oxygen as 16). The values varied between 19.93 and 19.98. The weight of a normal liter becomes 1.7813.

Holst and Hamburger ${ }^{23}$ found the percentage of nitrogen in argonnitrogen mixtures by two methods-(1) by absorbing out the nitrogen by means of a glow discharge in potassium vapor, and (2) with a baroscope.

In the latter method use is made of the difference in the upward force produced by the gas mixture on a glass body (volume about $300 \mathrm{cc}$ ) which was suspended from one arm of a balance as compared with an open glass vessel of an equal surface on the other arm. The apparatus was so devised that the arresting arrangement of the balance could also be put into action in a high vacuum. The pressures were read by means of a cathetometer. When using the value of 1.7809 for the density of argon in connection with the baroscope, they observed a systematic deviation from the results obtained by the other method. This deviation, which increased with the percentage of argon in the mixture, was largely eliminated by substituting Schultze's value for the density of argon. This tends to confirm the higher value for the density.

${ }^{21}$ Schultze, Ann. Physik, 48, p. 269, 1915; Holborn and Schultze, Ann. Physik, 47, p. 1089; 1915.

22 Fischer and Hahnel, Ber. Chem. Ges., 43, II, p. 1441; 1910.

${ }_{23}$ Holst and Hamburger, Proc. Acad. Sci. Amsterdam, 18, p. 872; 1916. 
Leduc ${ }^{24}$ in 1918 obtained 1.3787 as the specific gravity referred to air, using argon furnished by Claude, in which the neon and helium were removed by distillation with the aid of coconut charcoal. The gas was further purified by passing over calcium and copper oxide, potassium hydroxide, and phosphorus pentoxide. The weight of a normal liter derived from this result is 1.7825 .

The agreement between the results of Ramsay, Leduc, and Schultze leads to the choice of 1.7825 as the most probable value.

\section{CARBON DIOXIDE}

Regnault ${ }^{25}$ reported 1.52910 as the mean of five determinations of the specific gravity of carbon dioxide referred to air. The gas was prepared by the decomposition of white marble by hydrochloric acid and purified by passing through a solution of sodium bicarbonate and over pumice stone saturated with sulphuric acid. Crafts, ${ }^{26}$ applying a correction for the contraction of the balloon to this result of Regnault, changed it to 1.5290. Using the value for the weight of a normal liter of air chosen above, the weight obtained for a normal liter of carbon dioxide is 1.9768 .

Leduc, ${ }^{27}$ who prepared his gas in the same way, obtained as a mean of three very concordant determinations 1.52874 for the specific gravity referred to air. He believed that traces of air were possibly present and so chose 1.5288 as the best value. This leads to 1.9765 for the weight of a normal liter.

Rayleigh ${ }^{28}$ found 1.52909 for the specific gravity. No details were given as to the method used or the number of determinations. The gas was prepared by the action of hydrochloric acid on marble and on sodium carbonate. The weight of a normal liter deduced from his results is 1.9769 .

Guye and Pintza ${ }^{29}$ determined the density directly by the volumeter method, absorbing the gas completely in concentrated potassium hydroxide. The gas was obtained by the decomposition of sodium bicarbonate, and precautions were taken to remove all traces of air. The mean of three determinations with a maximum deviation of 1 part in 20,000 was 1.9769. The possible presence of air which Leduc mentions eliminates his results from consideration in the choice of the best value. Guye ${ }^{30}$ in his review chose 1.9769, which still appears to be the most reliable value.

as Leduc, Compt. rend., 167, p. 70; 1918.

${ }^{25}$ Regnault, Mém. de l'Académie, 21, p. 107; 1847.

${ }^{26}$ Crafts, Compt. rend., 106, p. 1662; 1888.

${ }_{27}$ Leduc, Ann. chim. phys. (7), 15, p. 34; 1898.

${ }_{28}$ Rayleigh, Proc. Roy. Soc. (London), 62, p. 204; 1S97; Nature, 57, p. $208 ; 1897$.

${ }^{29}$ Guye and Pintza, Compt. rend., 141, p. 51; 1905.

.30 Guye, J. Am. Chem. Soc., 30, p. 143; 1908. 


\section{CARBON MONOXIDE}

Leduc ${ }^{31}$ prepared carbon monoxide by the reaction between oxalic and sulphuric acids. To make sure that carbon dioxide was completely removed, he passed the gas through potassium hydroxide contained in pumice stone, in solution and in powdered form, and dried the gas over phosphorous pentoxide. As a mean of three determinations he obtained 0.96702 for the density referred to air, with a deviation of less than 1 in 20,000 .

Rayleigh ${ }^{32}$ at about the same time employed three methods for the preparation of the gas-(1) the action of sulphuric acid on crystallized potassium ferrocyanide, (2) the action of sulphuric acid on oxalic acid, and (3) the action of sulphuric acid on formic acid. The gas in all cases was purified by passing through an alkaline solution, over solid potassium hydroxide, and over phosphorus pentoxide. A very close agreement was obtained in the results from these three methods of preparation, giving as a mean 0.96716 for the specific gravity.

The weight of a normal liter according to Leduc is 1.2502 and according to Rayleigh 1.2504. Guye ${ }^{33}$ gave the preference to Rayleigh's value because the latter prepared the gas by three different reactions and made more determinations. The value accepted is therefore 1.2504 .

\section{CHLORINE}

Because of the difficulties arising from the great chemical activity of chlorine, the results of the different observers on the density of this gas vary quite widely. Gay-Lussac ${ }^{34}$ obtained 2.47 as its specific gravity referred to air. Bunsen a little later reported 2.4482. Ludwig ${ }^{35}$ and $\mathrm{Jahn}^{36}$ gave the values 2.4807 and 2.4821, respectively, as the specific gravity at $20^{\circ} \mathrm{C}$.

Leduc ${ }^{37}$ prepared chlorine in a glass apparatus from potassium bichromate and hydrochloric acid. Taking account of contamination by air, he reported the value 2.491 as the specific gravity but believed the result to have an accuracy no greater than 1 part in 2,500 . The corresponding weight of a normal liter is 3.220.

Moissan and Binet de Jassoneix ${ }^{38}$ made a great many determinations of the density of chlorine. The gas was prepared by the action of pure concentrated hydrochloric acid on manganese dioxide and was purified by washing in distilled water, removing the hydrogen

${ }^{31}$ Leduc, Ann. chim. phys. (7), 15, p. 33; 1898.

82 Rayleigh, Proc. Roy. Soc. (London), 62, p. 204; 1897.

${ }^{23}$ Guye, J. Am. Chem. Soc., 30, p. 143; 1908.

"Gay-Lussac, Recherches phys.-chim., 2, p. 125; 1811.

ss Ludwig, Ber. Chem. Ges., 1, p. 232; 1868.

${ }^{36} \mathrm{Jahn}$, Ber. Chem. Ges., 15, p. 1242; 1882.

${ }^{37}$ Leduc, Ann. chim. phys. (7), 15, p. 37; 1898.

${ }^{38}$ Moissan and Binet de Jassoneix, Compt rend., 137, p. 1198; 1903. 
chloride with porous manganese dioxide at a temperature of $50^{\circ} \mathrm{C}$., and drying with sulphuric acid and calcium chloride. The gas was then liquefied and solidified. The mean of six determinations gave 2.490 for the specific gravity, which leads to 3.219 as the weight of a normal liter.

Jaquerod and Tourpaian ${ }^{39}$ have carried out the most extensive investigations on this subject. They prepared the gas by three methods and measured the density in two ways. The gas was prepared (1) by the action of pure 20 per cent hydrochloric acid on precipitated manganese dioxide, (2) by the action of 38 per cent hydrochloric acid on pure potassium permanganate, and (3) by the decomposition of gold chloride in a glass tube heated to 300 to $350^{\circ} \mathrm{C}$. The chlorine in all cases was purified by passing through concentrated copper sulphate solution, sulphuric acid, and phosphorous pentoxide, after which it was liquefied, the chlorine was then evaporated and passed over sulphuric acid and phosphorous pentoxide. All parts of the purification apparatus in which the chlorine was not dry were protected from the light to prevent the formation of hydrochloric acid and oxygen.

The density of the chlorine prepared by the first two reactions was determined by the hydrostatic method. The results were very concordant, giving a mean of 2.8968 for the weight of a liter of chlorine at $15^{\circ} \mathrm{C}$. and $725 \mathrm{~mm}$. Only two successful observations were made by the volumeter method with chlorine prepared from gold chloride. The mean of these was 2.8961. The authors attached more weight to the first mean and reported 2.8965 as the most probable value. This gave 3.214 for the weight of a normal liter.

Because Jaquerod and Tourpaian used chlorine made in three ways, purified with extreme care, and because they determined the density by two methods, their value is considered the best at the present time.

\section{ETHANE}

Baume and Perrot ${ }^{40}$ determined the density of ethane which they prepared by the two methods-(1) by the electrolysis of a concentrated solution of sodium acetate, and (2) by the decomposition of ethyl magnesium iodide by water. In both cases the gas was purified with bromine water, potassium hydroxide, and phosphorus pentoxide. The mean of 13 determinations was 1.3566 for the weight of a normal liter of the gas prepared by the first method and 1.3563 for the gas prepared by the second. The authors were inclined to faror this latter result, because they suspected the presence of a slight amount of carbon dioxide in the electrolytic ethane, but waited for the results of Stahrfoss before making a final decision. 
In 1912 Leduc ${ }^{11}$ published a table of data which included the calculated and experimentally determined values for the specific gravity of various gases referred to air. For ethane the experimental value was 1.0494 and the calculated 1.0496 , which lead to the respective numbers 1.3567 and 1.3570 for the weight of a liter.

Stahrfoss ${ }^{42}$ also prepared ethane by the two methods-(1) by the decomposition of ethyl magnesium bromido by water, and (2) by a modification of the reaction of Frankland and Kolbe, dropping ethyl cyanide on sodium. The gas was purified in both cases with potassium hydroxide cooled to $0^{\circ} \mathrm{C}$., with concentrated sulphuric acid and with phosphorus pentoxide, followed by fractional distillation. The mean of seren determinations was 1.3566 for the weight of a normal liter. This result seems to justify the use of the mean of all the results of Baume and Perrot and of Leduc, which was also 1.3566 .

\section{ETHYLENE}

The determinations of the density of ethylene by Saussure ${ }^{43}$ and Bretschger ${ }^{44}$ are not important. Neither of these men purified the gas by liquefaction and fractional distillation. Leduc ${ }^{45}$ calculated the specific gravity but made no experimental determination. His result leads to the weight 1.2605 for the normal liter.

The ethylene used by Stahrfoss ${ }^{46}$ was prepared by the dehydration of ethyl alcohol with phosphoric acid and was purified with potassium hydroxide, concentrated sulphuric acid, and phosphorus pentoxide. Further purification was effected as usual by liquefaction and repeated distillation. The mean of six determinations was 1.2610. There is a slight question as to the accuracy of this result because of seasonal irregularities in the barometer which Stahrfoss could not explain.

Batuecas, ${ }^{47}$ following up the work of Stahrfoss, obtained ethylene by dehydrating ethyl alcohol in four different ways-(1) with metaphosphoric acid, purifying the gas by passing it through potassium hydroxide, a condenser cooled by a mixture of carbon dioxide and ether, potassium hydroxide again, sulphuric acid and phosphorus pentoxide; (2) with boric acid, purifying the gas with distilled water, potassium hydroxide, and a double tube of phosphorus pentoxide; (3) with sulphuric acid, purifying the gas with potassium hydroxide, solid and in solution, sulphuric acid, and phosphorus pentoxide; and (4) with aluminium or some aluminium compound, purifying it by physical means. The ethylene from all four methods was subjected

41 Leduc, Compt rend., 15̄, p. 206; 1912.

${ }^{2}$ Stahrfoss, J. chim. phys., 16, p. 175; 1918.

${ }^{3}$ Saussure, Ann. chim. 78, p. 57; 1811.

44 Bretschger, Inaugural Dissertation, Zurich, 1911.

${ }_{45}$ Leduc, Ann. chim phys. (7), 15, p. 94; 1898.

46 Stahrfoss, J. chim. phys., 16, p. 175; 1918.

${ }^{47}$ Batuecas, J. chim. phys., 16, p. 322; 1918. 
to the usual liquefaction and fractional distillation. The results of the density determinations were as follows:

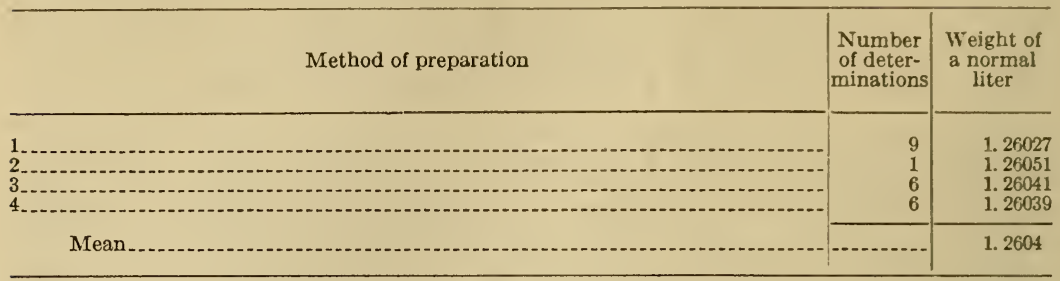

This value, 1.2604, is the most reliable one at the present time.

\section{FLUORINE}

Only two direct determinations of the density of fluorine appear to have been made, both by Moissan. ${ }^{48}$ In the first determination a small platinum flask was used to contain the fluorine. Later Moissan took advantage of the discovery that fluorine entirely free from hydrofluoric acid does not attack glass and made a more precise determination with the aid of a glass balloon. The weights were determined by comparison with chemically prepared nitrogen assumed to weigh 1.251, and correction was made for a rather large quantity of nitrogen occurring as an impurity. Four determinations gave 1.678, 1.705, 1.698, and 1.696 as the weight of a normal liter.

These results show rather large variations, although the mean, 1.694, is only slightly less than the density 1.695 computed from the atomic weight of fluorine 19.00 (International Committee, 1925). Inasmuch as the densities of other gases having approximately the same boiling point as fluorine are slightly greater than those calculated from the molecular weight (see fig. 1, p. 174), it seems adrisable to select 1.696 as the weight of a normal liter.

\section{HELIUM}

Before 1910 no accurate determinations had been made of the weight of a normal liter of helium. In the course of some previous researches on the liquefaction of helium the density had been observed as an indication of its purity.

Ramsay and Travers ${ }^{49}$ merely state that they obtained 1.98 (referred to oxygen as 16) for the density of helium. Since they used 1.4296 for the density of oxygen, their figure for the density of helium becomes 0.177 .

Watson, ${ }^{50}$ Heuse, ${ }^{51}$ and Taylor, ${ }^{52}$ all obtained helium from thorianite and purified it by passage over copper oxide and circulation over

${ }^{48}$ Moissan, Compt. rend., 109, p. 861; 1859; and 138, p. 728; 1904.

${ }^{4}$ Ramsay and Travers, Trans. Roy. Soc. (London) (A), 197, p. 47; 1901.

${ }^{50}$ Watson, J. Chem. Soc., 97, p. 810; 1910.

81 Heuse, Ber. physik. Ges., 15, p. $518 ; 1913$.

\$2 Taylor, Phys. Rev., 10, p. 653; 1917. 
coconut charcoal cooled by liquid air. Watson made only two determinations because of lack of time and did not claim very high accuracy for his mean, 0.1782. Heuse used a density bulb of about 547 ce capacity. The mean of seven very concordant results was $0.17857 \pm 0.00008$. Taylor determined the density in a new way by measuring the pressures required to bring a quartz microbalance to equilibrium in hydrogen, oxygen, and helium. The displacement of one scale division corresponded to a change of 1 part in 27,500 of the pressure required for equilibrium. The hydrogen and oxygen were prepared by the electrolysis of 15 per cent sodium hydroxide solution between nickel electrodes. The hydrogen was purified with red-hot copper, calcium chloride, and phosphorus pentoxide, and by circulation over charcoal at the temperature of liquid air. The oxygen was purified with copper oxide, calcium chloride, and phosphorus pentoxide. Four separate sets of observations were made with oxygen, two with hydrogen, and three with helium. From the comparison between helium and oxygen the weight of a normal liter of helium was computed to be 0.17850 ; from the comparison between helium and hydrogen 0.17848 was obtained. These values were later corrected by Guye ${ }^{53}$ to 0.17835 .

Baxter and Starkweather, ${ }^{54}$ starting with helium of about 95 per cent purity, subjected the gas to chemical purification by passing successively over hot copper, hot copper oxide, aqueous potassium hydroxide, solid potassium hydroxide, phosphorus pentoxide, hot copper, and hot calcium. The helium was further purified by repeated fractional adsorption on anhydrous chabazite ${ }^{55}$ at low temperature. The pressures were observed by means of mercury manometers communicating directly with the globes. Readings were made by setting the cross hairs of two horizonal telescopes of a Geneva cathetometer on the mercury levels and then by rotating the cathetometer through a small angle, observing the readings of the cross hairs on a standard meter bar. The temperatures of the barometers and the meter bar were carefully controlled. The mean of 12 observations was 0.17846 .

This value is almost the exact mean of the result obtained by Heuse and the corrected result of Taylor and is probably the most accurate determination. The value selected is 0.1785 .

\section{HYDROGEN}

Regnault ${ }^{56}$ made the first accurate determination of the density of hydrogen. Previously Dumas and Boussingault ${ }^{57}$ found that

${ }^{83}$ Guye, J. chim. phys., 16, p. 46; 1918.

4 Baxter and Starkweather, Proc. Nat. Acad. Sci., 11, p. 231; 1925.

ss Seeliger, Physik. Z., 22, p. 563; 1921.

36 Regnault, Mém. de l'Académie, 21, p. 143; 1869.

37 Dumas and Boussingault, Ann. chim. phys. (3), 8, p. 201; 1843. $83669^{\circ}-26-3$ 
the specific gravity referred to air was between 0.0691 and 0.0695 . The hydrogen used by Regnault was prepared by the action of hydrochloric acid on zinc and purified with moist potassium hydroxide, mercuric chloride, solid potassium hydroxide, and sulphuric acid. The mean of three determinations gave 0.08956 for the weight of a normal liter. Crafts ${ }^{58}$ applied a correction for the contraction of the balloon when evacuated which changed the value to 0.08984 . Rayleigh ${ }^{59}$ calculated a value from the ratio of the densities of oxygen and hydrogen, but it appears to be rather high.

Morley ${ }^{60}$ carried out a very extensive investigation on the subject. For all this work he prepared the gas by the electrolysis of sulphuric acid, purifying it with potassium hydroxide solution, incandescent copper, powdered potassium hydroxide, and phosphorus pentoxide. The gas was then absorbed in palladium which had been heated in vacuum and over which hydrogen had been passed while the palladium was too hot to absorb it. The gas was supplied directly to the balloons from the palladium for the first two series of experiments. After that the volumeter method was adopted. The hydrogen was weighed in the palladium and the volume measured at the temperature of melting ice in three balloons acting as a unit with a total capacity of 42 liters. The results are as follows:

\begin{tabular}{|c|c|c|}
\hline Series & $\begin{array}{c}\text { Number } \\
\text { of de- } \\
\text { termi- } \\
\text { nations }\end{array}$ & $\begin{array}{l}\text { Weight of a normal } \\
\text { liter }\end{array}$ \\
\hline $\begin{array}{l}1 \\
\end{array}$ & $\begin{array}{r}15 \\
19 \\
8 \\
4 \\
11\end{array}$ & $\begin{array}{l}0.089943 \pm 0.000007 \\
.089975 \pm .000011 \\
.089891 \pm .0000049 \\
.089885 \pm .0000088 \\
.089871+.0000034\end{array}$ \\
\hline
\end{tabular}

The results of the first two series were rejected because they were too high, probably because of the presence of mercury vapor in the evacuated balloons. The final weighted mean is $0.089878 \pm 0.0000027$.

A little later Leduc, ${ }^{61}$ preparing hydrogen by the electrolysis of a solution of potassium hydroxide and removing the oxygen with platinum sponge at red heat, obtained 0.06947 and 0.06949 as the results of two series of determinations of specific gravity referred to air. With hydrogen from commercial zinc and sulphuric acid he found 0.06947 for the specific gravity referred to air. This gives 0.08982 as the weight of a normal liter.

The very large number of Morley's observations and the extreme precautions which he used were considered in choosing the value 0.08988 as the most reliable.

\footnotetext{
${ }^{68}$ Crafts, Compt. rend., 106, p. 1662; 1888.

${ }^{60}$ Rayleigh, Proc. Roy. Soc. (London), 43, p. 356; 1888; 50, p. 448; 1892.

60 Morley, Smithsonian Contribution to Knowledge, 29, 1895; Am. Chem. J., 17, p. 267; 1895; Z. Physik. Chem., 20, p. 271; 1896.

61 Leduc, Ann. chim. phys. (7), 15, p. 28; 1898.
} 


\section{HYDROGEN BROMIDE}

The determinations of the density of hydrogen bromide made by Löwig, ${ }^{62}$ Strecker, ${ }^{63}$ and Biltz ${ }^{64}$ are of historical interest only. The more recent work of Baume and Perrot ${ }^{65}$ was carried out with all the precautions known at that time. Their result for the weight of a normal liter was 3.630 .

Moles, ${ }^{68}$ Murray, ${ }^{67}$ and Reiman ${ }^{68}$ all determined the density of hydrobromic acid gas at Geneva in 1916, following the procedure outlined by Guye. ${ }^{69}$

Moles prepared the gas by four methods-(1) hydrolysis of phosphorus bromide, (2) action of hydrogen sulphide on moist bromine, (3) action of bromine on naphthalene, and (4) action of bromine on paraffin at 190 to $200^{\circ} \mathrm{C}$. In all cases the excess bromine was removed with naphthalene or paraffin and the gas was dried with melted calcium bromide, calcined aluminium oxide, and condensed at $-60^{\circ} \mathrm{C}$. instead of drying with phosphorus pentoxide because of the possible chemical action between hydrogen bromide and the latter reagent. The gas was then scrubbed with a small amount of liquid hydrogen bromide and fractionally distilled. The mean of 33 determinations18 with gas prepared by the first, 6 by the second, 6 by the third, and 3 by the fourth method-was $3.6446 \pm 0.0001$ for the weight of a normal liter. This figure was checked by recalculations in a later article. ${ }^{70}$

Reiman employed entirely different methods in preparing hydrogen bromide-(1) direct synthesis from hydrogen and bromine followed by distillation of an aqueous solution of the gas and treatment with phosphorus pentoxide, (2) direct synthesis with immediate liquefaction and fractional distillation of hydrogen bromide without phosphorus pentoxide, and (3) double decomposition of potassium bromide and phosphoric acid followed by purification as in the second method. Final purification was effected by scrubbing the gas in a small amount of liquid hydrogen bromide and by fractional distillation. The mean of 31 determinations-21 with gas prepared by the first, 6 by the second, and 4 by the third method-was found to be $3.6444 \pm 0.00014$ for the weight of a normal liter.

Although the work of Murray was carried on with the same care as that of Moles and Reiman, less importance was attached to his value of $3.6443 \pm 0.0004$ than to the values obtained by the other two on

\footnotetext{
62 Löwig, Bromine and Its Chemical Behavior, Heidelberg, p. 234; 1829

a Strecker, Wied. Ann., 13, p. 20; 1881.

of Biltz, Z. physik. Chem., 10, p. 354; 1892.

os Baume and Perrot, Archiv. sci. phys. nat. (4), 26, 1908.

${ }^{66}$ Moles, J. chim. phys., 14, p. 389; 1916.

67 Murray, J. chim. phys., 15, p. 334; 1917.

${ }^{68}$ Reiman, J. chim. phys., 15, p. 293; 1917.

${ }^{60}$ Guye, J. chim. phys., 14, p. 361; 1916.

70 Moles, J. chim. phys., 19, p. 135; 1921.
} 
account of a defect of his balance. Maass and Russell ${ }^{71}$ found the density by the volumeter method. Their result, 3.6397, is uncorrected for gravity and was obtained with a gas not carefully purified.

The results obtained by Moles and by Reiman appear equally reliable. Therefore, a mean of their values, or 3.6445 , is chosen as the most probable value for the weight of a normal liter.

\section{HYDROGEN CHLORIDE}

Leduc ${ }^{72}$ found a value of 1.2692 for the specific gravity of hydrogen chloride referred to air which gives 1.6409 for the weight of a normal liter. The gas was obtained by the action of pure sulphuric acid on pure sodium chloride and purified only with phosphorus pentoxide.

Guye and Ter Gazarian, ${ }^{73}$ working at the Geneva laboratory, employed the balloon method, using only one balloon and gas prepared from sulphuric acid and sodium chloride, dried with sulphuric acid, liquefied, and fractionally distilled. The mean of four determinations with an extreme variation of 9 in 10,000 was 1.6399 for the weight of a normal liter.

Gray, ${ }^{74}$ working in London with gas prepared by the same method, obtained as a mean of six experiments 1.6398 , the probable error being 3.7 in 10,000 .

In his review Guye ${ }^{75}$ takes the mean of these last two values, 1.6399 , as the most reliable. Since that time two extensive investigations have been made-one by Gray and Burt ${ }^{76}$ and the other by Scheuer. ${ }^{77}$ These seem to point to a lower value for the density of hydrogen chloride.

The first two authors prepared the gas by three different reactions(1) sulphuric acid on sodium chloride, (2) sulphuric acid on ammonium chloride, and (3) silicon tetrachloride and water. The gas was dried and condensed, then fractionally distilled many times. Pure paraffin was substituted for the ordinary stopcock lubricant because it was not attacked by hydrochloric acid so quickly. A source of error was the adsorption of the gas by the walls of the glass balloon. Gray and Burt, after careful investigation, found that an appreciable amount was adsorbed even when the containers were apparently perfectly dry. They determined the value of that amount for $1 \mathrm{~cm}^{2}$ of surface at different pressures of filling the balloons and applied it as a correction to their results. This correction was $0.00013 \mathrm{gm}$ per liter. They found the density by the volumeter method, condensing the gas on coconut charcoal. Although the

\footnotetext{
${ }^{71}$ Maass and Russell, J. Am. Chem. Soc., 40, p. 1847; 1918.

${ }_{72}$ Leduc, Ann. chim. phys. (7), 15, p. 36; 1898.

${ }^{73}$ Guye and Ter Gazarian, Compt. rend., 143, p. 1233; 1906.

${ }^{4}$ Gray, Proc. Chem. Soc., 23, p. 119; 1907.

75 Guye, J. Am. Chem. Soc., 30, p. 143; 1908.

70 Gray and Burt, J. Chem. Soc., 95, p. 1633; 1909.

77 Scheuer, Z. physik. Chem., 68, p. 575; 1909.
} 
individual results were not as close as might be desired, the means for the density of the gas prepared by the three methods agreed very well, 1.64003, 1.64010, and 1.64016, the mean being 1.64010 . This is the weight of a liter in London. Correcting this to standard gravity ( $\mathrm{g}=9 \mathrm{S0} 0.665)$ it becomes $1.63923 \pm 0.00005$.

Scheuer carried out an exhaustive research on the subject, making 28 determinations on gas prepared by the action of concentrated sulphuric acid on sodium chloride, dried with sulphuric acid, condensed, passed over phosphorus pentoxide and fractionally distilled. In order to detect any adsorption of the gas by the glass surface he used five balloons of different sizes. There was no consistent difference in the results as there should have been if some gas were adsorbed, but a slight amount was found to enter into solid solution or chemical composition with the glass, an amount which had no effect on the results. The mean of his 28 determinations was $1.63952 \pm 0.00004$.

Scheuer did not believe that Gray and Burt were justified in applying the correction for adsorption of the gas by the glass walls. In answer to this criticism these authors ${ }^{78}$ instituted another series of experiments to eliminate the error from adsorption. In this series they displaced the gas in the density bulb by clean mercury, keeping the pressure as nearly atmospheric as possible. The gas was prepared by the action of phosphoric acid on ammonium chloride. The agreement between the individual results of the series was much better than had been obtained before by either Scheuer or themselves. The mean of 10 determinations was 1.63923 , in exact agreement with the mean of their former results.

Later Scheuer ${ }^{79}$ carefully repeated his work, using gas prepared by two reactions-(1) sulphuric acid on ammonium chloride, and (2) sulphuric acid on sodium chloride. He found, as before, that there were no consistent differences in the values obtained with balloons of different sizes or with different pressures (allowing for the compressibility of the gas) and concluded that the error due to adsorption was not greater than the mean probable error, which was 0.000025 . This disagreement regarding the effect of adsorption throws doubt on the accuracy of this correction. The mean of his 24 determinations was 1.63925 .

The agreement of his result with those of Gray and Burt justifies the selection of 1.6392 for the weight of a normal liter.

\section{HYDROGEN SULPHIDE}

Leduc $^{80}$ was the first to make a reliable determination of the density of hydrogen sulphide. He was not entirely satisfied with

79 Gray and Burt, Chem. News, 103, pp. 161, 170; 1911.

79 Scheuer, Sitz. Akad. Wiss. Wien., IIA, 123, p. 931; 1914.

so Leduc, Ann. chim. phys. (7), 15, p. 36; 1898. 
the purity of the gas which he obtained by the action of pure hydrochloric acid on crystallized antimony sulphide. The carbon dioxide was completely removed, but a trace of hydrogen was thought to remain. He gave 1.1895 as the most probable value of the specific gravity referred to air, which corresponds to 1.5379 for the weight of a normal liter.

The gas used by Baume and Perrot ${ }^{81}$ was prepared by the reaction of hydrochloric acid on four different sulphides-on iron sulphides, both commercial and precipitated; on antimony sulphide; and on sodium sulphide. The final purification was, as usual, by liquefaction and fractional distillation. On account of the action of the hydrogen sulphide on mercury a differential oil manometer was substituted for the ordinary mercury one. The mean of 18 determinations was 1.5393 for the weight of a normal liter.

This value is chosen in preference to Leduc's because of the purity of the gas and the number of determinations. The authors also point out that the atomic weight of sulphur derived from this value agrees within 1 in 6,000 with the atomic weight of sulphur found by the gravimetric method by Richards and Jones.

Until this value is checked by other determinations it does not. seem advisable to carry the figures beyond the third decimal place. The accepted value is 1.539 .

\section{KRYPTON}

Krypton, isolated from the air by a long series of fractionations, is. probably the most difficult of the rare gases to prepare in a pure state because of the necessity of removing traces of both the lower boiling argon and the higher boiling xenon.

Ramsay and Travers ${ }^{82}$ were able to obtain only 12 cc of the gas, too small a quantity to purify completely or to weigh accurately. Their best determination of the density (referred to oxygen as 16) was 40.81 .

Moore $^{83}$ was able to collect larger quantities, so that he could work with a density bulb of 32.7077 cc. He carried on fractionai distillation until two samples gave concordant results for density, and the spectroscope showed no evidence of impurity. The two values obtained (referred to oxygen as 16) were 41.507 and 41.504. From Moore's observations Watson ${ }^{84}$ computed the weight of a. normal liter to be 3.708. This is, without question, the best result that has been obtained. The last figure, however, is rather doubtful.

81 Baume and Perrot, J. chim. phys., 6, p. 610; 1908.

82 Ramsay and Travers, Trans. Roy. Soc. (London), 197, p. 47; 1901.

${ }_{83}$ Moore, J. Chem. Soc., 93, p. 2181; 1908.

\& Watson, J. Chem. Soc., 97, p. 833; 1910. 
16. METHANE

The results of Thomson, ${ }^{85}$ Schloesing, ${ }^{88}$ and Moissan and Chavanne ${ }^{87}$ are of historical interest only. They found the specific gravity of methane referred to air to be $0.558,0.558$, and 0.555 , respectively.

Baume and Perrot ${ }^{88}$ at Genera determined the density of methane which was prepared by the action of water on methyl magnesium iodide and was purified by passing through water, potassium hydroxide, sulphuric acid and phosphorus pentoxide, and by fractional distillation. Particular precautions were taken to remove air. The mean of nine determinations was 0.7168 for the weight of a normal liter, in exact agreement with Leduc's ${ }^{80}$ calculated value. Inasmuch as the extreme rariation in the results amounted to 0.0012 , the accuracy of the fourth figure is questionable.

Keyes, Smith, and Joubert, ${ }^{90}$ extrapolating from their equation of state, obtained 0.7172 .

Preference is given to the direct determination of Baume and Perrot, inasmuch as the equation of state of Keys and his coworkers has not been sufficiently established to render such an extrapolated value reliable. The value selected is therefore 0.7168 , the last figure being considered doubtful.

\section{METHYL CHLORIDE}

Baume ${ }^{21}$ determined the density of methyl chloride which was prepared by the action of hydrochloric acid on methyl alcohol and was purified only by liquefaction and fractional distillation. The mean of eight determinations was 2.3046 for the weight of a normal liter with a maximum variation of 0.0008 . Dumas and Peligot ${ }^{22}$ reported a value of 2.2543 . The methods for giving the most accurate results, however, were not known at that time.

Shorthose ${ }^{93}$ obtained 2.287 as a mean of four determinations, the extreme values being 2.283 and 2.292. These values were reduced to $0^{\circ} \mathrm{C}$. and $760 \mathrm{~mm}$ by assuming the perfect gas law and no definite statement is made regarding the actual temperature and pressure at which the determinations were made.

Batuecas ${ }^{94}$ prepared methyl chloride by two methods-(1) by the reaction between phosphorous trichloride and methyl alcohol, a

8s Thomson, Gmelin Handb.

80 Schloesing, Compt. rend., 122, p. 398; 1896.

${ }^{87}$ Moissan and Chavanne, Compt. rend., 140, p. 407; 1905.

${ }^{89}$ Baume and Perrot, J. chim. phys., 7, p. 368; 1909; Compt. rend., 148, p. 39; 1909.

${ }^{89}$ Leduc, Ann. chim. phys. (7), 15, p. 94; 1898.

${ }^{0}$ Keyes, Smith, and Joubert, J. Math. Phys. Mass. Inst. Tech., 1, p. 191; 1922.

भI Baume, J. chim. phys., 6, p. 1; 1908.

${ }^{2}$ Dumas and Peligot, Ann. chim. phys., 58, p. 27; 1835.

${ }_{93}$ Shorthose, Dept. Sci. Ind. Research (London), Food Investigation Board Report No. 19, 1924.

94 Batuecas, Compt. rend., 180, p. 1929; 1925; Anales Soc. españ. fis. quím., 23, p. 343; 1925. 
method studied by Walker and Johnson, ${ }^{95}$ and (2) by the thermal decomposition of tetramethylammonium chloride. The gas obtained by the first method was passed through two bubblers of dilute sodium hydroxide to remove hydrochloric acid and two bubblers of concentrated sulphuric acid. Further purification was effected by repeated fractional distillation. The methyl chloride obtained by the second method was washed with concentrated sulphuric acid to retain the trimethylamine which is also formed. The gas was then submitted to repeated fractional distillations.

The mean of 17 determinations was 2.3085 for the weight of a normal liter. The values vary from 2.3073 to 2.3100 . This value is appreciably higher than that obtained by Baume (2.3046).

While Batuecas made more determinations than did Baume, the results of the latter were subject to less variation. It therefore appears best to select the mean of the two values and discard the figure in the fourth decimal place. The value selected for the weight of a normal liter is therefore 2.307 .

\section{METHYL ETHER}

Baume ${ }^{96}$ prepared methyl ether according to the method described by Leduc ${ }^{97}$-by the action of methyl alcohol and concentrated sulphuric acid, washing the gas in sulphuric acid and drying with phosphorus pentoxide, then distilling it eight times. The mean of 13 determinations was 2.1097 for the weight of a normal liter. This is quite different from the value of Dumas and Peligot ${ }^{98}$ (2.0568), but in fair agreement with Leduc's calculated value of 2.1085 and Maass and Russell's ${ }^{99}$ experimental value, 2.1103 , which was obtained with gas not well purified.

Batuecas ${ }^{1}$ prepared methyl ether by two methods. The first depended upon the catalytic action of aluminum, heated to redness, on the vapor of methyl alcohol. The gas was passed through concentrated potassium hydroxide and then through a condenser maintained at $-10^{\circ}$ C., after which it was dried with phosphorus pentoxide and subjected to several fractional distillations.

The second method, the method used by Baume, consisted of heating a mixture of concentrated sulphuric acid and methyl alcohol to 80 to $90^{\circ} \mathrm{C}$. The gas was passed through a condenser cooled with ice and salt, dried with phosphorus pentoxide, and fractionally distilled.

The determinations were made by the balloon method, the pressures being measured to $0.1 \mathrm{~mm}$ and the weights to $0.05 \mathrm{mg}$. The

os Walker and Johnson, J. Chem. Soc., 87, p. 1692; 1905.

96 Baume, J. chim. phys., 6, p. 1; 1908.

${ }^{27}$ Leduc, Ann. chim. phys. (7), 15, p. 73; 1898.

${ }^{98}$ Dumas and Peligot, Ann. chim. phys., 68, p. 27; 1835.

" Marss and Russell, J. Am. Chem. Soc., 40, p. 1847; 1918.

1 Batuecas, Compt. rend., 179, p. 440; 1924. 
mean of 20 determinations, 2.109s, is in excellent agreement with the value obtained by Baume, and is selected as the best value.

\section{METHYL FLUORIDE}

Methyl fluoride was prepared by Moissan and Meslans ${ }^{2}$ by the action of methyl iodide on silver fluoride and purified by passing through a condenser at $-50^{\circ} \mathrm{C}$. and again over silver fluoride at a temperature of $90^{\circ} \mathrm{C}$. The observed specific gravity of the gas referred to air was 1.22 , which corresponds to 1.577 as the weight of a normal liter.

J. N. Collie ${ }^{3}$ found that heat decomposed tetramethylammonium fluoride into methyl fluoride and trimethylamine. The methyl fluoride was solidified and the impurities remaining in the vapor phase were removed by evacuation. A rough determination gave the density 16.95 compared with hydrogen, which corresponds to 1.523 for the weight of a normal liter.

Moles and Batuecas ${ }^{4}$ employed two methods of preparation-(1) by heating a mixture of potassium methyl sulphate and potassium fluoride to 160 to $200^{\circ} \mathrm{C}$., and (2) by Moissan's method, passing methyl iodide vapor over anhydrous silver fluoride at about $90^{\circ} \mathrm{C}$. The latter method gave gas of constant density after the methyl fluoride had been passed about a dozen times over silver fluoride. Thirty-three determinations gave a mean of 1.5455 for the weight of a normal liter. Moles and Batuecas ${ }^{5}$ later, using new values for the latitude and elevation and for the contraction of the balloon when evacuated, corrected this weight of a normal liter to 1.5452

\section{NEON}

The separation of helium from neon is an extremely difficult task. It can be effected by neither solution nor diffusion processes. Ramsay and Travers ${ }^{6}$ succeeded in purifying neon by the fractionation of the liquefied gases with liquid hydrogen. Their value for the weight of a normal liter, 0.891, is, however, lower than the values found by Watson ${ }^{7}$ and later by Leduc. ${ }^{8}$

Both of these later observers removed the helium by means of charcoal cooled by liquid air. Since the separation from argon is a relatively simple matter, and since the only impurity is helium, the higher values are considered the more reliable. Watson reported 0.9002 as a mean of 10 determinations, of which the maximum variation was 1 in 1,000 . Leduc made only two determinations of the

${ }^{2}$ Moissan and Meslans, Compt. rend., 107, p. 1155; 1888.

${ }^{3}$ Collie, J. Chem. Soc., 85, p. 1317; 1904.

'Moles and Batuecas, J. chim. phys., 17, p. 537; 1919.

s Moles and Batuecas, J. chim. phys., 18, p. 353; 1920.

- Ramsay and Travers, Trans. Roy. Soc. (London), 197, p. 47; 1901.

7 Watson, J. Chem. Soc., 97, p. 810; 1910.

8 Leduc, Compt. rend., 158, p. 864; 1914. 
specific gravity referred to air. The mean 0.6961 corresponds to 0.9000 as the weight of a normal liter. The greater number of determinations and the care which Watson took in purifying the neon lead to the choice of his value, 0.9002. The last figure is doubtful.

\section{NITRIC OXIDE}

The results of early investigators on the specific gravity of nitric oxide referred to air vary widely, Thomson giving 1.041, Berard 1.08S, Davy 1.094, and Kirwan 1.1887. Leduc ${ }^{9}$ reported the value 1.0387 which he probably regarded as correct to within one in the fourth decimal place, but in the gas there was an unknown impurity for which he made only an approximate correction. His observation leads to the value 1.3429 as the weight of a normal liter.

One of the reasons for the lack of agreement in the values for the density is the difficulty in obtaining the gas free from nitrogen and nitrous oxide. Gray, ${ }^{10}$ who prepared it from potassium nitrite, potassium ferrocyanide, and acetic acid, washed it with potassium hydroxide, dried it with phsophorus pentoxide, and took especial precautions in the fractional distillation to get rid of both of these impurities. The nitrous oxide was removed largely by bubbling the gas through its own liquid, the nitrogen by cooling the gas below its sublimation point at a pressure less than $170 \mathrm{~mm}$. Under these conditions there was solidification without liquefaction, and the nitrogen was thus prevented from dissolving in the liquefied gas. The weight of the gas was compared with an equal rolume of oxygen. The value for the weight of a normal liter calculated from the mean of 10 determinations was 1.3402 .

Guye and Davila ${ }^{11}$ also took precautionary measures to remore nitrogen and nitrous oxide. The gas was prepared by three different methods-(1) decomposition of a sulphuric acid solution of sodium nitrite or nitrate with mercury, (2) reduction of nitric acid or sodium nitrite with ferrous sulphate, and (3) decomposition of sodium nitrite by sulphuric acid. The results were as follows:



Scheuer ${ }^{12}$ prepared nitric oxide by two methods-(1) the action of sulphuric acid on sodium nitrite, and (2) the decomposition of

${ }^{9}$ Leduc, Compt. rend., 116, p. 322; 1893.

${ }_{10}$ Gray, J. Chem. Soc., 87, p. 1601; 1905.

11 Guye and Davila, Compt. rend., 141, p. 826; 1905; Mém. Genère, 35, p. 648; 190 S.

12 Scheuer, Sitz. Akad. Wiss. Wien., 123, p. 931; 1914. 
nitrogen tetroxide by water. The gas was very carefully purified, and determinations were made by both the balloon and the rolumeter methods. The mean of 24 determinations was 1.34021 .

The close agreement of this result with those of Gray and of Guye and Davila justifies the choice of 1.3402 as the most accurate value.

\section{CHEMICAL NITROGEN}

Up to the time of Rayleigh in 1892 no determinations had been made of the density of chemically pure nitrogen. Rayleigh ${ }^{13}$ noticed that the gas prepared from air by the elimination of oxygen gave a value considerably higher than gas prepared by the decomposition of ammonia. At first he tried to explain the difference by the presence of impurities in the lighter gas. Ramsay became interested in the problem, and the discovery of argon and its isolation from atmospheric air resulted. Working at first alone and then with Ramsay, Rayleigh prepared chemically pure nitrogen by five different methods-(1) reduction of nitric oxide by hot iron; (2) reduction of nitrous oxide by hot iron; (3) decomposition of ammonium nitrite, gas purified by iron at red heat; (4) decomposition of urea by sodium hypobromite; and (5) decomposition of ammonium nitrite gas. A summary of the results is as follows:

\begin{tabular}{|c|c|c|}
\hline Method & $\begin{array}{l}\text { Number of } \\
\text { determina- } \\
\text { tions }\end{array}$ & $\begin{array}{l}\text { Weight } \\
\text { of a nor- } \\
\text { mal liter }\end{array}$ \\
\hline $\begin{array}{l}1 \\
4 \\
4\end{array}$ & $\begin{array}{l}4 \\
2 \\
2 \\
4 \\
3\end{array}$ & $\begin{array}{l}1.2514 \\
1.2508 \\
1.2507 \\
1.2505 \\
1.2507\end{array}$ \\
\hline Mean & $\cdots$ & 1. 2508 \\
\hline
\end{tabular}

Leduc ${ }^{14}$ obtained chemically pure nitrogen in four ways-(1) by decomposition of ammonium nitrite; (2) by decomposition of ammonium nitrite by heat; (3) by reduction of nitrogen dioxide by incandescent copper; and (4) by decomposition of ammonia by incandescent copper oxide. The number of determinations is not mentioned. The mean giren is 0.9671 , which corresponds to 1.2503 for the weight of a normal liter.

Gray ${ }^{15}$ obtained nitrogen by decomposing nitric oxide with nickel and compared its weight with that of oxygen prepared from pure recrystallized potassium permanganate. The weight of a normal liter calculated from the mean of two determinations, using the accepted value for oxygen 1.4290, was 1.2506.

\footnotetext{
${ }_{13}$ Rayleigh, Nature, 46, p. 512; 1892; Proc. Roy. Soc. (London), 53, p. 134; 1893; Proc. Roy. Soc. (London) 55, p. 340; 1894. Rayleigh and Ramsay, Trans. Roy. Soc. (London), 186, p. 189; 1895. Rayleigh, Nature 57, p. 20 ; 1898 .

14 Leduc, Ann. chim. phys. (7), 15, p. 33; 1898.

15 Gray, J. Chem. Soc., 87, p. 1615; 1905.
} 
Moles ${ }^{16}$ prepared nitrogen by heating sodium trinitride, $\mathrm{NaN}_{3}$, which had been recrystallized 50 times. The pure salt was dried in vacuum by means of phosphorus pentoxide. The mean of four determinations is 1.2507 .

Moles, ${ }^{17}$ working with Clavera, later repeated his earlier measurements and obtained 1.25048 for the weight of a normal liter. The value which these observers recommend after a consideration of the other determinations is 1.25057. This is probably the best value at the present time. The last figure is quite uncertain.

\section{ATMOSPHERIC NITROGEN}

Rayleigh, ${ }^{18}$ whose investigations of the densities of atmospheric and of chemically prepared nitrogen led to the discovery of the inert gases, reviewed the important determinations of the density of atmospheric nitrogen prior to his investigation and corrected all the results to a common basis. He further pointed out the fact that the absolute determination of density was subject to more errors than the determination of relative density, and for that reason he attached enough importance to specific gravities referred to air to quote the specific gravity obtained by each observer.

Rayleigh referred all results to the latitude of Paris using $g=980.939$. The direct determinations, as corrected by him, have been reduced to the standard value of gravity $(\mathrm{g}=980.665)$ and are given in the second column of Table 2. The third column contains the density of atmospheric nitrogen computed from the specific gravities given by Rayleigh by multiplying by the average value, 1.29293, for the density of air selected in this paper.

TABLE 2.-Direct determinations of the density of atmospheric nitrogen

[Corrected to $\mathrm{g}=980.665$ ]

\begin{tabular}{l} 
Observer \\
\hline
\end{tabular}

Only the first result attributed to Rayleigh was given in his original article. The other two values were obtained in the course of experi-

${ }_{16}$ Moles, J. chim. phys., 19, p. 283; 1921.

17 Moles and Clavera, J. chim. phys., 21, p. 11; 1924.

is Rayleigh, Proc. Roy. Soc. (London), 53, p. 139; 1893. 
ments planned to ascertain the reason for the difference between chemical and atmospheric nitrogen. ${ }^{19}$ In each case the reagent used for removing the oxygen is given.

Paya and Moles ${ }^{20}$ at Madrid passed air through alkaline pyrogallol solution prepared as indicated by Hempel, ${ }^{21}$ and then through a solution of ammoniacal cuprous chloride. The gas was then passed through concentrated sulphuric acid after which it was led through a hard glass tube about a meter long filled with copper turnings. This tube was kept at red heat by means of an elcctric furnace. Any carbon monoxide liberated by the pyrogallol solution was absorbed by the ammoniacal cuprous chloride solution, the ammonia from which was in turn absorbed by the sulphuric acid. The mean of 10 determinations, which varied from 1.25676 to 1.25697 , was $1.2568 s$.

It might prove of interest to compare this value of the density of atmospheric nitrogen with that calculated from the observed density of air, the density of oxygen, and the average percentage of oxygen in the air.

A selection of what appear to be the most reliable determinations of the oxygen content of normal air is given in Table 3.

TABLE 3.-Percentage of oxygen in. air freed fro $m$ carbon dioxide and water vapor

\begin{tabular}{|c|c|c|c|c|}
\hline Date & $\begin{array}{l}\text { Oxygen } \\
\text { by vol- } \\
\text { ume }\end{array}$ & Method of analysis & $\begin{array}{l}\text { Number } \\
\text { of anal- } \\
\text { yses }\end{array}$ & Observer \\
\hline $\begin{array}{l}1852 \\
1864-65 \\
1878 \\
1881 \\
1885\end{array}$ & $\begin{array}{r}\text { Per cent } \\
20.950 \\
20.952 \\
20.951 \\
20.955 \\
20.930\end{array}$ & $\begin{array}{l}\text { Hydrogen eudiometer } \\
\text { Potassium pyrogallate. }\end{array}$ & $\begin{array}{r}180 \\
169 \\
17 \\
778 \\
90\end{array}$ & \multirow{3}{*}{$\begin{array}{l}\text { Regnault. } \\
\text { Smith. } \\
\text { Leeds. } \\
\text { Morley. } \\
\text { Hempel. } \\
\text { Morley. } \\
\text { Hempei. } \\
\text { Benedict. } \\
\text { Boothby and Sandi- } \\
\text { ford. }\end{array}$} \\
\hline 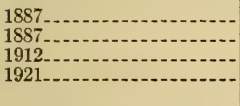 & $\begin{array}{l}20.933 \\
20.900 \\
20.951 \\
20.927\end{array}$ & $\begin{array}{l}\text { Hydrogen eudiometer } \\
\text { Potassium pyrogallate... }\end{array}$ & $\begin{array}{r}89 \\
91 \\
255 \\
974\end{array}$ & \\
\hline Weighted mean.. & 20.940 & Total .. & 2,643 & \\
\hline
\end{tabular}

The analyses of Regnault were originally given in percentages of the air containing carbon dioxide. Regnault did not determine carbon dioxide in all samples, hence the average percentage of oxygen which he found, 20.956, is here corrected for the amount of carbon dioxide normally present in the air. In making the above selection only the results obtained by men known to be competent analysts, using methods shown by experience to be accurate, have been included. All analyses of samples suspected to represent other than normal air have been omitted, as have all samples not taken within

${ }^{19}$ Rayleigh, Proc. Roy. Soc. (London), 55, p. 304; 1894.

${ }^{20}$ Paya and Moles, Anales. soc. españ. fís. quím., 20, p. 247; 1922.

${ }^{21}$ Hempel, Gasanalytische Methoden, p. 133. 
the North Temperate Zone. The mean value of the 2,643 analyses is 20.940 .

Using the following values for the densities of air and of oxygen

$$
\begin{aligned}
d(\text { air }) & =1.29293 \\
d(\text { oxygen }) & =1.42904
\end{aligned}
$$

The density of atmospheric nitrogen is computed to be 1.25688 . This is in exact agreement with the mean value obtained by Paya and Moles. Since we are justified in using only five significant figures, as in the case of air, the selected value is taken to be 1.2569.

\section{NITROUS OXIDE}

The difficulty in determining the density of nitrous oxide accurately is in removing all traces of nitrogen. Rayleigh ${ }^{22}$ attempted to do this in two ways-(1) by dissolving the nitrous oxide in water and expelling it from the solution, and (2) by fractional distillation. $\mathrm{He}$ obtained nitrous oxide from the commercial product supplied in the liquid state in iron cylinders. The mean of two experiments on the gas expelled from water was 3.6356 for the weight of the gas in the balloon. The mean of three experiments on the fractionally distilled gas was 3.6362. A few years later ${ }^{23}$ he solidified nitrous oxide with liquid air, evacuated the space abore it, allowed the gas to evaporate into the balloon, and repeated the process. The mean of three determinations with a maximum variation of 11 in 100,000 was 3.6365. This gives as the weight of a normal liter, 1.9778.

Leduc ${ }^{24}$ obtained a slightly higher value. He used commercial nitrous oxide, subjecting it to fractional distillation. The specific gravities referred to air were found to be 1.5304, 1.5298, and 1.5301; mean 1.5301, which corresponded to 1.9782 for the weight of a normal liter.

Guye and Pintza ${ }^{25}$ prepared the gas by the decomposition of hydroxylamine sulphate with sodium nitrite and purified it chemically with potassium hydroxide, sulphuric acid, and phosphorus pentoxide. They found the density by the volumeter method, condensing the gas on charcoal to weigh it. The mean of three determinations with a maximum deviation of 3 in 20,000 was $1.9779 \mathrm{~S}$. They applied a correction for compressibility which brought the value down to 1.9775 .

The mean of the results of Rayleigh, Leduc, and Guye and Pintza is 1.9778 , which agrees exactly with Rayleigh's value and is the one accepted. The last significant figure is doubtful.

${ }_{22}$ Rayleigh, Proc. Roy. Soc. (London), 62, p. 204; 1897.

${ }^{23}$ Rayleigh, Proc. Roy. Soc. (London), 74, p. 181; 1904.

24 Leduc, Ann. Chim. Phys. (7), 15, p. 35; 1898.

25 Guye and Pintza, Compt. rend., 139, p. 677; 1904. 


\section{OXYGEN}

Both Germann ${ }^{26}$ and Moles ${ }^{27}$ have given very complete reviews of the literature on the density of oxygen.

Germann chose as most worthy of consideration those of Rayleigh and Morley. Taking these into account, but attaching more weight to his own because of the use of four barometers and fractional distillation, he concluded that 1.42912 was the most accurate value.

Moles recalculated the observations of Morley, Rayleigh, Leduc, and Gray by introducing corrections regarding the density of water, the value for the acceleration of gravity, and the coefficient of expansion of oxygen. These corrected values are included in the second column of Table 4. His arerage for all the values including his own gires 1.42898 as the weight of the normal liter of oxygen. Later, working with Crespi, he corrected his value to 1.42902.

The mean of all the results, excluding those of the observers prior to Rayleigh, is 1.42904, and this value is selected for the weight of a normal liter of oxygen. The disagreement between the various. observers, however, renders doubtful the figure in the last decimal place.

TABLE 4.-Important determinations of the weight of a normal liter of oxygen

\begin{tabular}{|c|c|c|c|c|}
\hline \multirow{2}{*}{ Date } & \multicolumn{2}{|c|}{$\begin{array}{l}\text { Weight of a normal } \\
\text { liter of oxygen }\end{array}$} & \multirow{2}{*}{ Observer } & \multirow{2}{*}{ Reference } \\
\hline & $g=980.616$ & $y=980.665$ & & \\
\hline 806 & 1.43353 & 1. 43360 & Biot and $A$ & \multirow{18}{*}{ 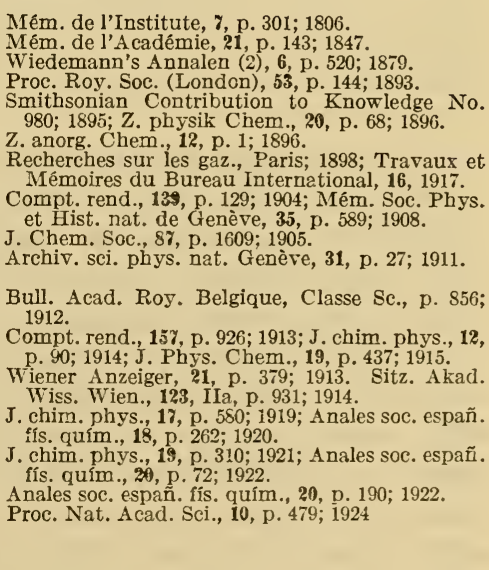 } \\
\hline & 1.4293 & & & \\
\hline & 1.42896 & 1. 42903 & von Jolly. & \\
\hline & 1.42894 & 1. 42901 & Rayleigh_. & \\
\hline & $* 1.42892$ & 1.42899 & Morley & \\
\hline $\begin{array}{l}1596 \ldots \\
1898 \ldots\end{array}$ & $\begin{array}{l}1.42906 \\
* 1: 4288\end{array}$ & $\begin{array}{l}1.42913 \\
1.4289\end{array}$ & Thomsen & \\
\hline & & & & \\
\hline 1904 & 1.4292 & 1.4293 & Jaquerod and Pintza.- & \\
\hline 1905 & ${ }^{*} 1.42891$ & 1.42898 & Gray.. & \\
\hline & 1.4289 & 1.4290 & $\begin{array}{l}\text { Jaquerod and Tour- } \\
\text { paian. }\end{array}$ & \\
\hline 1912 & 1.42578 & 1.42885 & $\begin{array}{l}\text { Bruylants and Byte- } \\
\text { bier. }\end{array}$ & \\
\hline 1913 & 1.42905 & 1. 42912 & Germann............... & \\
\hline 1913 & ${ }^{*} 1.42910$ & 1. 42917 & Scheuer...... & \\
\hline 1920 & ${ }^{*} 1.42890$ & 1.42897 & Moles and Batuecas.. & \\
\hline 1921. & 1.42891 & 1. 42898 & Moles and Gonzales... & \\
\hline $\begin{array}{l}1922 .- \\
1924_{-}\end{array}$ & $\begin{array}{l}1.42895 \\
1.42901\end{array}$ & $\begin{array}{l}1.42902 \\
1.42908\end{array}$ & $\begin{array}{l}\text { Moles and Crespi } \\
\text { Baxter and Stark- }\end{array}$ & \\
\hline Selec & 1.42897 & 1.42904 & weather. & \\
\hline & & & & \\
\hline
\end{tabular}

NotE.-Asterisks indicate values corrected by Moles. All values given in the second column are calculated using $g=980.616$. The values in the third column are based upon $g=980.665$.

${ }^{26}$ Germann, J. Phys. Chem., 19, p. $437 ; 1915$.

27 Moles, J. chim. phys., 19, p. 100; 1921. 


\section{PHOSPHINE}

Although several different values for the density of phosphine are given in the older textbooks and tables of constants, apparently the only direct determination prior to 1909 was that made by Dumas in 1828. He found the weight of a liter to be $1.523 \mathrm{~g}$.

Leduc ${ }^{28}$ calculated the specific gravity with respect to air as 1.1845 , which leads to 1.5314 as the weight of a normal liter.

Ter Gazarian ${ }^{29}$ carried out a modern research on the subject. He prepared the gas by the action of water on pure calcium phosphide and purified it chemically and by fractional distillation. As a mean of six determinations, from which the greatest deviation was 1 part in 6,000 , he obtained 1.5294 for the weight of a normal liter. Additional determinations are necessary to establish the accuracy of the last figure.

\section{PROPANE}

Timmermans ${ }^{30}$ appears to be the only one who has made a careful determination of the density of propane. He used two methods of preparation-(1) the reaction between propyl iodide and sodiumammonium, $\mathrm{NaNH}_{3}$, suggested by Lebeau, ${ }^{31}$ purifying the gas first chemically and then by fractional distillation; and (2) the reaction between propyl cyanide and sodium, purifying only by fractional distillation. The following results were obtained:

\begin{tabular}{l|r|r|r}
\hline Method of preparation & $\begin{array}{r}\text { Number } \\
\text { of deter- } \\
\text { minations }\end{array}$ & $\begin{array}{r}\text { Weight of } \\
\text { a normal } \\
\text { liter }\end{array}$ \\
\hline 1 & & 10 & 2.01962 \\
\hline
\end{tabular}

This work was later repeated ${ }^{32}$ with the utmost care in purifying the samples. The propyl iodide was purified by fractionating over phosphorus pentoxide. It distilled at $102.4^{\circ} \pm 0.05^{\circ} \mathrm{C}$. The gas was passed through concentrated sulphuric acid, bromine water, potassium hydroxide solution, and then over solid potassium hydroxide. After liquefying to remove air it was passed through an acid solution of vanadium sulphate to remove propylene. It was then dried over phosphorus pentoxide, liquefied, and fractionated four times. Air was then removed by boiling vigorously. The above procedure was carried out twice and the gas thus obtained fractionated eight times, using the middle part of the last fraction for making

${ }^{28}$ Leduc, Ann. chim. phys. (7), 15, p. $94 ; 1898$.

${ }_{29}$ Ter Gazarian, J. chim. phys., 7, p. 337; 1909.

${ }^{30}$ Timmermans, Compt. rend., 158, p. 789; 1914.

${ }^{31}$ Lebeau, Compt. rend., 140, p. 1042; 1905.

32 Timmermans, J. chim. phys., 18, p. 133; 1920. 
the determinations. The propane prepared by the second method was fractionated 10 times. The results given by 'Timmermans are as follows:

\begin{tabular}{|c|c|c|c|}
\hline Method of preparation & & $\begin{array}{l}\text { Number } \\
\text { of deter- } \\
\text { minations }\end{array}$ & $\begin{array}{l}\text { Weight of } \\
\text { a normal } \\
\text { liter }\end{array}$ \\
\hline 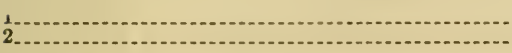 & & $\begin{array}{r}16 \\
8\end{array}$ & $\begin{array}{l}\text { 2. } 01996 \\
\text { 2. } 01998\end{array}$ \\
\hline Weighted mean.... & & $\ldots$ & 2. 01998 \\
\hline
\end{tabular}

The individual values varied from 2.0172 to 2.0233 . One series of determinations on the gas prepared by the second method is left out because of the fact that the weights of the bulbs before and after filling did not agree. The value recommended is 2.020.

\section{SILICON TETRAFLUORIDE}

The determination of the density of silicon tetrafluoride is complicated by the difficulty of obtaining a pure sample and by the fact that the gas, unless it is very dry, attacks glass.

Dary, ${ }^{33}$ Dumas, $^{34}$ and Truchot ${ }^{35}$ found $3.5735,3.6$, and 3.6, respectively, as the specific gravity referred to air.

Jaquerod and Tourpaian ${ }^{36}$ carried out a careful determination of the density. The gas, prepared by heating barium fluosilicate, was purified by passing over glass wool at $100^{\circ} \mathrm{C}$. to remove the hydrogen fluoride and over phosphorus pentoxide to dry it and by distilling from the solid state. They found the density by the hydrostatic method and by the balloon method, the results of the two checking very well. The mean of all gave as the weight of a normal liter 4.693 .

Germann and Booth ${ }^{37}$ prepared silicon tetrafluoride by the action of sulphuric acid on calcium fluoride and silicon dioxide. It was purified with glass wool and phosphorus pentoxide, liquefied under pressure, and distilled from the liquid, as these authors found that distillation from the solid did not yield pure gas because of the minute solid particles carried over by the stream of gas. The same gas was used repeatedly with further purification between determinations until the results finally showed no change in the density. The mean of six determinations was 4.6842 for the weight of a normal liter.

The difference between this value and that of Jaquerod and Tourpaian must be due to impurities in the gas and not to the methods

${ }^{33}$ Davy, Trans. Roy. Soc. (London) 102, p. 352; 1812.

${ }_{4}$ Dumas, Ann. chim. phys. (2), 33, p. 370; 1826.

as Truchot, Compt. rend., 98, p. $821 ; 1884$.

${ }^{36}$ Jaquerod and Tourpaian, J. chim. phys., 11, p. 3; 1913.

a7 Germann and Booth, J. Phys. Chem., 21, p. 81; 1917. 
used for determining densities, for these methods have given satisfactory results with other gases. Jaquerod and Tourpaian found that with red-hot glass wool the density was too high, probably because of the formation of sesquifluoride. They gave no proof that it was not formed when the glass wool was at $100^{\circ}$ C. Germann and Booth showed that hydrogen fluoride was removed successfully at ordinary temperatures and also that distillation from the solid did not give gas of constant purity. Because of these facts they believed that their value, 4.684, was more nearly correct, and it is their value which is accepted. The figure in the last decimal place is doubtful.

\section{SULPHUR DIOXIDE}

Guye ${ }^{38}$ in his review of researches on the densities of gases discussed the results obtained for sulphur dioxide up to 1908.

Leduc's ${ }^{39}$ value referred to air is 2.2639 , which gives 2.9269 as the weight of a normal liter. The gas was prepared by the action of mercury on pure sulphuric acid.

Jaquerod and Pintza, ${ }^{40}$ using the volumeter method and gas prepared by repeated fractional distillation of commercial sulphur dioxide, found as the weight of a normal liter, 2.9267 .

Baume ${ }^{41}$ obtained the gas also by fractional distillations of commercial sulphur dioxide but determined the density by the balloon method. His result is 2.9267 for the weight of a normal liter.

Since 1908 Scheuer, ${ }^{42}$ using both the balloon and volumeter methods, has made some careful determinations upon highly purified material. In 1912 he obtained for the mean of 16 determinations the value 2.9269. The mean of 40 determinations made in 1914 was 2.92689 , and this is probably the best value, although it does not appear justifiable to carry the accuracy beyond that of the fourth decimal place. "The selected value is therefore 2.9269 .

\section{XENON}

Xenon can be isolated from air only by a long series of fractionations, and the quantity present is exceedingly minute. Ramsay and Travers ${ }^{43}$ were able to obtain only $3 \mathrm{ec}$ of the gas which they purified and weighed with such accuracy as the small sample permitted. Moore ${ }^{44}$ obtained a much larger quantity of the gas, which he fractionated until the spectroscope showed no trace of impurity and again condensed and fractionated at a lower temperature. His balloon had a volume of about $33 \mathrm{cc}$. Two determinations of the density (referred to oxygen as 16) gave 65.380 and 65.32S. From these

38 Guye, J. Am. Chem. Soc., 30, p. 143; 1908.

${ }^{39}$ Leduc, Ann. chim. phys. (7), 15, p. 39; 1898.

40 Jaquerod and Pintza, Compt. rend., 139, p. 129; 1904.

41 Baume, J. chim. phys., 6, p. 1; 1908.

49 Scheuer, Chem. Zeit., 36, p. 394; 1912; Sitz. Akad. Wiss. Wien., 123, p. 931; 1914.

${ }^{43}$ Ramsay and Travers, Trans. Roy. Soc. (London), 197, p. 47; 1901.

${ }^{44}$ Moore, J. Chem. Soc., 93, p. 2181; 1908. 
results, applying a correction for gravity, Watson ${ }^{45}$ has computed the weight of a normal liter to be 5.851. The figure in the last decimal place is doubtful.

\section{CONCLUSION}

The selected value for the weight of a normal liter of each of the gases considered above is given in Table 5. Each of these values has been very carefully determined and approaches the limit of accuracy obtainable with the methods in use at the present time. The figures written as subscripts are of doubtful accuracy.

Table 6 presents a collection of values of densities of gases which, for one reason or another, can not be regarded as possessing the same degree of reliability as those presented in Table 5. In most cases results are available from only one observer, hence no effort has been made to examine the data critically. A considerable number of experimental values for other gases have found their way into various tables of physical constants, but in nearly every case the determination was an approximate one made for the purpose of identifying the compound and is less reliable than the density computed from the atomic weights of the component elements and the deriations from a perfect gas, as indicated in Figure 1, page 174 .

If all gases conformed to Boyle's law, $p v=N R T$, where $p$ is the pressure, $v$ the volume, $N$ the number of mols, $R$ a constant, and $T$ the absolute temperature, then $1 \mathrm{~mol}$. of every gas would occupy the same volume at the same temperature and pressure. It can be shown from the experimental data on the density and compressibility of oxygen for which the data are best known that the volume of $1 \mathrm{~g}$ molecule of a perfect gas would be 22.414 liters at $0^{\circ} \mathrm{C}$. and $760 \mathrm{~mm}$ of pressure. The density of any gas would, therefore, be $\frac{M}{22.414} \mathrm{~g}$ per liter $\left(0^{\circ} \mathrm{C}\right.$., $\left.760 \mathrm{~mm}\right)$.

None of the gases, however, exactly follow Boyle's law; the deviations at $0^{\circ} \mathrm{C}$. and $760 \mathrm{~mm}$ sometimes amounting to over 3 per cent. Upon comparing the densities of the various gases with those calculated from the molecular weights it is at once noticed that the deriations are smallest for those gases having the lowest boiling points (Table 7).

These deviations for various gases are plotted against the corresponding boiling points in Figure 1. For convenience the deviations are represented by the following formula

where

$$
\left(\frac{L_{\mathrm{n}}}{L}-1\right) 100
$$

$$
\begin{aligned}
& L_{\mathrm{n}}=\text { observed weight of a normal liter } \\
& L=\frac{M}{22.414}
\end{aligned}
$$

The gases corresponding to the numbers assigned to the various points are shown in Table 7 . 




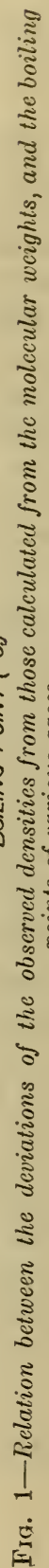


It will be observed that several of the points, especially those representing some of the gases listed in Table 6, deviate quite markedly from those involving gases having similar boiling points and whose densities are well established.

The deviations of several of the organic compounds, notably acetylene, ethylene, methyl fluoride, and propane are also rather large, which suggests that the observed densities are a little high.

Such a graph, therefore, while representing an approximate relation only, nevertheless becomes useful by indicating the general reliability of the observed data as well as by providing means for calculating the densities of gases for which no experimental data are arailable.

\section{TABLE 5.-Selected values of the weights of a normal liler of various gases}

$\left[L_{\mathrm{n}}=\right.$ Weight in grams of a normal liter of gas at $0^{\circ} \mathrm{C}$. ancl at a pressure of $760 \mathrm{~mm}$ of mercury (at $0^{\circ} \mathrm{C}$.), the acceleration of gravity being taken as $980.665 \mathrm{~cm}$ per second per second]

\begin{tabular}{|c|c|c|c|c|}
\hline Gas & Formula & $\begin{array}{l}\text { Molecu- } \\
\text { lar } \\
\text { weight } 1\end{array}$ & $L_{\mathbf{n}}$ & $\begin{array}{c}\text { Specific } \\
\text { gravity, } \\
\text { air }=1\end{array}$ \\
\hline $\begin{array}{l}\text { A cctylene } \\
\text { Air } \\
\text { A mmonia. } \\
\text { Argon } \\
\text { Carbon dioxide. } \\
\text { Carbon monoxide. }\end{array}$ & $\mathrm{C}_{\mathrm{C}} \mathrm{C}_{2} \mathrm{H}_{2}$ & 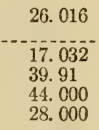 & $\begin{array}{l}\text { 1. } 179 \\
\text { 1. } 2929 \\
.7710 \\
\text { 1. } 7825 \\
\text { 1. } 9769 \\
\text { 1. } 2504\end{array}$ & $\begin{array}{l}0.912 \\
1.0000 \\
.5963 \\
1.3787 \\
1.5290 \\
.9671\end{array}$ \\
\hline $\begin{array}{l}\text { Chlorine } \\
\text { Ethane } \\
\text { Ethylene } \\
\text { Fluorine } \\
\text { Helium }\end{array}$ & 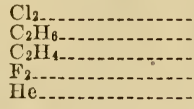 & $\begin{array}{l}\text { 70. } 914 \\
30.048 \\
28.032 \\
38.00 \\
4.00\end{array}$ & $\begin{array}{l}\text { 3. } 214 \\
\text { 1. } 3566 \\
\text { 1. } 2604 \\
\text { 1. } 696 \\
.1785\end{array}$ & $\begin{array}{l}\text { 2. } 486 \\
1.0493 \\
.9749 \\
1.312 \\
.1381\end{array}$ \\
\hline $\begin{array}{l}\text { Hydrogen } \\
\text { Hydrogen bromide } \\
\text { Hydrogen chloride } \\
\text { Hydrogen sulphide } \\
\text { Krypton }\end{array}$ & $\mathrm{H}_{2}^{\mathrm{H}} \mathrm{S}$ & $\begin{array}{l}\text { 2. } 016 \\
80.924 \\
36.465 \\
34.080 \\
82.9\end{array}$ & $\begin{array}{l}.08988 \\
\text { 3. } 6445 \\
\text { 1. } 6392 \\
\text { 1. } 539 \\
\text { 3. } 70_{8}\end{array}$ & $\begin{array}{l}.08952 \\
2.8189 \\
1.2678 \\
1.190 \\
2.868\end{array}$ \\
\hline $\begin{array}{l}\text { Methane } \\
\text { Methyl chloride. } \\
\text { Methyl ether } \\
\text { Methyl fluoride. } \\
\text { Neon }\end{array}$ & $\begin{array}{l}\mathrm{CH} \\
\mathrm{CH}_{3} \mathrm{Cl}_{3} \\
\left(\mathrm{CH}_{3}\right)_{2} \mathrm{O}_{2} \\
\mathrm{CH} \mathrm{NH}_{3} \mathrm{~F}_{2}\end{array}$ & $\begin{array}{l}\text { 16. } 032 \\
50.481 \\
46.048 \\
34.02 \\
20.2\end{array}$ & $\begin{array}{l}.7168 \\
2.307 \\
2.1098 \\
1.5452 \\
.9002\end{array}$ & $\begin{array}{l}.5544 \\
\text { 1. } 784 \\
\text { 1. } 6318 \\
\text { 1. } 1951 \\
.6963\end{array}$ \\
\hline $\begin{array}{l}\text { Nitric oxide } \\
\text { Nitrogen (chemical) } \\
\text { Nitrogen (atm.) } \\
\text { Nitrous oxide } \\
\text { Oxygen }\end{array}$ & $\mathrm{N}_{2} \mathrm{~N}_{2} \mathrm{O}_{2}$ & $\begin{array}{r}30.008 \\
28.016 \\
44.016 \\
32.000\end{array}$ & $\begin{array}{l}\text { 1. } 3402 \\
\text { 1. } 25057 \\
\text { 1. } 2569 \\
\text { 1. } 9778 \\
\text { 1. } 4290_{4}\end{array}$ & $\begin{array}{l}\text { 1. } 0366 \\
.9672_{4} \\
.9722 \\
\text { 1. } 5297 \\
\text { 1. } 10527\end{array}$ \\
\hline $\begin{array}{l}\text { Phosphine } \\
\text { Propane } \\
\text { Silicon tetrafluoride } \\
\text { Sulphur dioxide. } \\
\text { Xenon }\end{array}$ & $\begin{array}{l}\mathrm{PH}_{3} \\
\mathrm{C}_{3} \mathrm{H}_{8} \\
\mathrm{SiF}_{4} \\
\mathrm{SO}_{2}+\ldots+2\end{array}$ & $\begin{array}{l}\text { 34. } 051 \\
44.064 \\
104.06 \\
64.064 \\
130.2\end{array}$ & $\begin{array}{l}\text { 1. } 529_{4} \\
\text { 2. } 020 \\
\text { 4. } 68_{4} \\
2.9269 \\
5.85_{1}\end{array}$ & $\begin{array}{l}\text { 1. } 182_{9} \\
\text { 1. } 562 \\
3.62_{3} \\
\text { 2. } 2638 \\
\text { 4. } 52_{6}\end{array}$ \\
\hline
\end{tabular}

1 From International Table of Atomic Weights for 1925. 
TABLE 6.-Values for densities of gases which have not been determined with great accuracy

\begin{tabular}{|c|c|c|c|c|}
\hline Gas & Formula & $L_{\mathrm{a}}$ & $\begin{array}{l}\text { Specific } \\
\text { gravity, } \\
\text { air }-1\end{array}$ & Authority \\
\hline $\begin{array}{l}\text { Arsine } \\
\text { Isobutane } \\
\text { Carbon oxysulphiderine monoxide } \\
\text { Monogermane }\end{array}$ & $\begin{array}{l}\mathrm{AsH} \\
\mathrm{C}_{4} \mathrm{H}_{10} \ldots \ldots \\
\mathrm{COS} \\
\mathrm{Cl}_{2} \mathrm{O} \ldots \\
\mathrm{GeH}_{1} \ldots \ldots\end{array}$ & $\begin{array}{l}\text { 3. } 48 \\
\text { 2. } 673 \\
\text { 2. } 72 \\
\text { 3. } 89 \\
\text { 3. } 420\end{array}$ & $\begin{array}{l}\text { 2. } 69 \\
\text { 2. } 067 \\
\text { 2. } 10 \\
\text { 3. } 01 \\
\text { 2. } 645\end{array}$ & $\begin{array}{l}\text { Dumas. } \\
\text { Ouedinoff. } \\
\text { Than. } \\
\text { Garzarolli and Schacherl. } \\
\text { Corey, Laubengayer, and Dennis. }\end{array}$ \\
\hline $\begin{array}{l}\text { Hydrogen iodide } \\
\text { Hydrogen selenide } \\
\text { Hydrogen telluride. } \\
\text { Monomethylamine.... } \\
\text { Trimethyl boride. }\end{array}$ & $\begin{array}{l}\mathrm{HI} \\
\mathrm{H}_{2} \mathrm{Se}_{2} \\
\mathrm{H}_{2} \mathrm{Te} \\
\mathrm{CH}_{3} \mathrm{NH}_{2} \\
\left(\mathrm{CH}_{3}\right)_{3} \mathrm{~B}_{2 .}\end{array}$ & 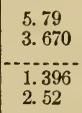 & $\begin{array}{l}\text { 4. } 48 \\
\text { 2. } 839 \\
\text { 1. } 49 \\
\text { 1. } 080 \\
1.95\end{array}$ & $\begin{array}{l}\text { Cuthbertson and Cuthbertson. } \\
\text { Bruylants and Dondeyne. } \\
\text { Ernyei. } \\
\text { Muller. } \\
\text { Stock and Zeidler. }\end{array}$ \\
\hline $\begin{array}{l}\text { "Nadon" } \\
\text { Nitrosyl chloride } \\
\text { Phosphorus pentafiuoride }\end{array}$ & $\begin{array}{l}\mathrm{Nt} \\
\mathrm{Rd} \\
\mathrm{NO} \mathrm{Cl}_{5}\end{array}$ & $\begin{array}{l}9.73 \\
2.992 \\
5.81\end{array}$ & $\begin{array}{l}\text { 7. } 53 \\
2.314 \\
4.49\end{array}$ & $\begin{array}{l}\text { Gray and Ramsay. } \\
\text { Wourtzel. } \\
\text { Moissan (1). }\end{array}$ \\
\hline $\begin{array}{l}\text { Phosphorus oxyfluoride } \\
\text { Monosilane } \\
\text { Disilane }\end{array}$ & $\begin{array}{l}\mathrm{POF}_{3} \ldots \ldots \\
\mathrm{SiH}_{4} \ldots \ldots \\
\mathrm{Si}_{2} \mathrm{H}_{6} \\
\mathrm{SbH}_{3} \ldots \ldots\end{array}$ & $\begin{array}{l}4.8 \\
1.44 \\
2.85 \\
25.30\end{array}$ & $\begin{array}{l}3.7 \\
1.11 \\
2.20\end{array}$ & $\begin{array}{l}\text { Moissan (2). } \\
\text { Stock and Somieski. } \\
\text { Do. } \\
\text { Stock and Guttman. }\end{array}$ \\
\hline
\end{tabular}

${ }^{1}$ At $3^{\circ} \mathrm{C} . ;$ air at $3^{\circ} \mathrm{C} .=1$.

$2 \mathrm{G} / 115^{\circ} \mathrm{C} ., 754 \mathrm{~mm}$

Bruylants and Dondeyne, Bull. sci. acad. roy. Belg., p. 387; 1922.

Corey, Laubengayer, and Dennis, J. Am. Chem. Soc., 47, p. 112; 1925.

Cuthbertson and Cuthbertson, Trans. Roy. Soc. (London), 218 A, p. 13; 1913

Dumas, Ann. chim. phys., 33, p. 355; 1826; 44, p. 288; 1830; Pogg. Ann., 9, p. 308; 1827.

Ernyei, Z. anorg. Chem., 25, p. 317; 1900.

Garzarolli and Schacherl, Lieb. Ann., 258, p. 273; 1885.

Gray and Ramsay, Proc. Roy. Soc. (London), 84, p. 536; 1911.

Moissan (1), Compt. rend., 191, p. 1490; 1885.

Moissan (2), Compt. rend., 162, p. 1245; 1886.

Muller, Ann. chim. phys., 20, p. 123; 1910.

Ouedinoff, Bull. soc. chim. Belg., 23, p. 266; 1909.

Stock and Guttman, Ber. Chem. Ges., 37, I, p. 885; 1904.

Stock and Somieski, Ber. Chem. Ges., 19 I, p. 111; 1916.

Stock and Zeidler, Ber. Chem. Ges., 54, p. 534; 1921.

Than, Ann. chim. phys., 15, p. 459; 1868.

Wourtzel, Compt. rend., 155, p. 152; 1912; J. chim. phys., 11, p. 29; 1913. 
TABLE 7.-The deviations of the observed densities $\left(L_{\mathrm{n}}\right)$ from those calculated from the molecular wcights, and the boiling points of various gases

$L=\frac{M . W t}{22.414}$.

\begin{tabular}{|c|c|c|c|c|c|}
\hline No. & Gas & $L$ & $L_{\mathrm{n}}$ & $\left(\frac{L_{\mathrm{n}}}{L}-1\right) 100$ & $\begin{array}{l}\text { Boiling } \\
\text { point }\end{array}$ \\
\hline $\begin{array}{l}1 \\
2 \\
3 \\
4 \\
5\end{array}$ & $\begin{array}{l}\text { A cetylene } \\
\text { Ammonia } \\
\text { Argon } \\
\text { Carbon dioxide } \\
\text { Carbon monoxide... }\end{array}$ & $\begin{array}{l}1.1607 \\
.7599 \\
1.781 \\
1.9631 \\
1.2492\end{array}$ & $\begin{array}{l}1.179 \\
.7710 \\
1.7825 \\
1.9769 \\
1.2504\end{array}$ & $\begin{array}{l}1.58 \\
1.46 \\
.11 \\
.705 \\
.094\end{array}$ & $\begin{array}{l}{ }^{\circ} \mathrm{C} . \\
-84 \\
-33 \\
=186 \\
=78 \\
-192\end{array}$ \\
\hline \begin{tabular}{r|}
6 \\
7 \\
8 \\
9 \\
10
\end{tabular} & $\begin{array}{l}\text { Chlorine } \\
\text { Ethane } \\
\text { Ethylene } \\
\text { Fluorine- } \\
\text { Helium }\end{array}$ & $\begin{array}{l}\text { 3. } 1638 \\
1.3406 \\
1.2506 \\
1.6954 \\
.1785\end{array}$ & $\begin{array}{l}\text { 3. } 214 \\
1.3566 \\
1.2604 \\
1.696 \\
.1785\end{array}$ & $\begin{array}{l}1.59 \\
1.19 \\
.78 \\
.04 \\
.0\end{array}$ & $\begin{array}{l}-34 \\
-88 \\
-104 \\
-187 \\
-269\end{array}$ \\
\hline $\begin{array}{l}11 \\
12 \\
13 \\
14 \\
15\end{array}$ & 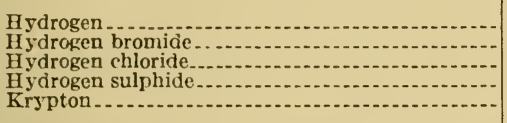 & $\begin{array}{l}.08994 \\
\text { 3. } 6104 \\
1.6269 \\
1.5205 \\
3.699\end{array}$ & $\begin{array}{l}.08988 \\
\text { 3. } 6445 \\
1.6392 \\
1.539 \\
\text { 3. } 708\end{array}$ & $\begin{array}{l}-.07 \\
.838 \\
.76 \\
1.22 \\
.2\end{array}$ & $\begin{array}{l}-253 \\
-69 \\
-84 \\
-62 \\
-152\end{array}$ \\
\hline $\begin{array}{l}16 \\
17 \\
18 \\
19 \\
20\end{array}$ & 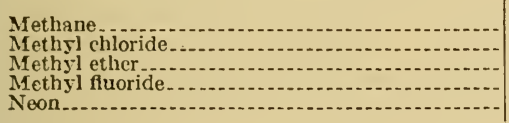 & $\begin{array}{l}.71527 \\
2.2522 \\
2.0544 \\
1.5178 \\
.901\end{array}$ & $\begin{array}{l}.7168 \\
2.307 \\
2.1038 \\
1.5452 \\
.9002\end{array}$ & $\begin{array}{l}.21 \\
2.43 \\
2.69 \\
1.80 \\
-.1\end{array}$ & $\begin{array}{l}-162 \\
-24 \\
-24 \\
-78 \\
-243\end{array}$ \\
\hline $\begin{array}{l}21 \\
22 \\
23 \\
24 \\
25\end{array}$ & $\begin{array}{l}\text { Nitric oxide } \\
\text { Nitrogen } \\
\text { Nitrous oxide. } \\
\text { Oxygen } \\
\text { Phosphine............... }\end{array}$ & $\begin{array}{l}1.33881 \\
1.24993 \\
1.96377 \\
1.42768 \\
1.51918\end{array}$ & $\begin{array}{l}1.3402 \\
1.25057 \\
1.9778 \\
1.42904 \\
1.5294\end{array}$ & $\begin{array}{l}.10 \\
.051 \\
.714 \\
.095 \\
.67\end{array}$ & $\begin{array}{l}-151 \\
-196 \\
-89 \\
=183 \\
-87\end{array}$ \\
\hline $\begin{array}{l}26 \\
27 \\
28 \\
29 \\
30\end{array}$ &  & $\begin{array}{l}1.9659 \\
4.6426 \\
2.8582 \\
5.809 \\
3.479\end{array}$ & $\begin{array}{l}2.020 \\
4.684 \\
2.9269 \\
5.851 \\
3.48\end{array}$ & $\begin{array}{r}2.75 \\
.89 \\
2.40 \\
.72 \\
.03\end{array}$ & $\begin{array}{l}-44 \\
-107 \\
-10 \\
-109 \\
-55\end{array}$ \\
\hline $\begin{array}{l}31 \\
32 \\
33 \\
31\end{array}$ & $\begin{array}{l}\text { Isobutane } \\
\text { Carbon oxysulphide } \\
\text { Chlorine monoxide } \\
\text { Monogermane }\end{array}$ & $\begin{array}{l}2.591 \\
2.680 \\
3.878 \\
3.419\end{array}$ & $\begin{array}{l}2.673 \\
2.72 \\
3.89 \\
3.420\end{array}$ & $\begin{array}{l}3.16 \\
1.5 \\
.3 \\
.03\end{array}$ & $\begin{array}{l}-13 \\
-50 \\
-5 \\
-90\end{array}$ \\
\hline $\begin{array}{l}35 \\
36 \\
37 \\
38\end{array}$ & $\begin{array}{l}\text { Hydrogen iodide } \\
\text { Hydrogen selenide } \\
\text { Monomethylamine } \\
\text { Nitrosylehloride. }\end{array}$ & $\begin{array}{l}5.708 \\
3.578 \\
1.385 \\
2.9207\end{array}$ & $\begin{array}{l}5.79 \\
3.670 \\
1.396 \\
2.992\end{array}$ & $\begin{array}{l}1.4 \\
2.6 \\
.8 \\
2.4\end{array}$ & $\begin{array}{l}-37 \\
-41 \\
-7 \\
-6\end{array}$ \\
\hline $\begin{array}{l}39 \\
40 \\
41 \\
42\end{array}$ &  & $\begin{array}{l}5.623 \\
4.64 \\
1.432 \\
2.774\end{array}$ & $\begin{array}{l}5.81 \\
4.8 \\
1.44 \\
2.85\end{array}$ & $\begin{array}{l}3.3 \\
3.4 \\
.6 \\
2.7\end{array}$ & $\begin{array}{l}-75 \\
-40 \\
-112 \\
-14\end{array}$ \\
\hline
\end{tabular}

Washington, August 31, 1925. 



